\title{
Energy demand, substitution and environmental taxation: An econometric analysis of eight subsectors of the Danish economy
}

\author{
Møller, Niels Framroze
}

Published in:

Energy Economics

Link to article, DOI:

10.1016/j.eneco.2016.10.004

Publication date:

2017

Document Version

Peer reviewed version

Link back to DTU Orbit

Citation (APA):

Møller, N. F. (2017). Energy demand, substitution and environmental taxation: An econometric analysis of eight subsectors of the Danish economy. Energy Economics, 61, 97-109. https://doi.org/10.1016/j.eneco.2016.10.004

\section{General rights}

Copyright and moral rights for the publications made accessible in the public portal are retained by the authors and/or other copyright owners and it is a condition of accessing publications that users recognise and abide by the legal requirements associated with these rights.

- Users may download and print one copy of any publication from the public portal for the purpose of private study or research.

- You may not further distribute the material or use it for any profit-making activity or commercial gain

- You may freely distribute the URL identifying the publication in the public portal 


\title{
Energy Demand, Substitution and Environmental Taxation: An econometric analysis of eight subsectors of the Danish economy
}

\author{
Niels Framroze Møller ${ }^{\mathrm{a}}$ \\ ${ }^{a}$ Technical University of Denmark, Management Engineering \\ Produktionstorvet, Building 426, room 130A, DK - 2800 Lyngby, Denmark \\ Email address: nfmo@dtu.dk
}

\begin{abstract}
This research contains an econometric analysis of energy demand in trade and industry which allows for substitution between electricity and other energy carriers when relative prices change. The presence of substitution suggests that taxation can be a means of changing the energy input mix in a more environmental-friendly direction. For eight subsectors of the Danish economy, time series (1966-2011) are modeled by means of partial Cointegrated VARs. Long-run demand relations are identified for all subsectors and robust price elasticities are supported in five cases. The results are used in a small impulse-response experiment which suggests a potential for taxation to induce substitution of electricity for fossil-based energy.

Key words: Industrial energy demand, Energy substitution, Cointegrated VAR, Environmental taxes, PSO tariff, Impulse-response analysis.

JEL: codes: C3, H2, Q4.
\end{abstract}

\section{Introduction}

In many European countries energy systems are in a state of flux, transitioning away from fossilbased energy towards renewable-based systems. The developments are comprehensive and concern the way in which energy is both produced and consumed. On the supply side, electricity production based on Renewable Energy (RE) sources, like wind, solar, wave, geothermal and tidal, is making substantial progress, and for more than a decade, massive investments in RE generation capacity have already been undertaken in many EU countries. ${ }^{1}$ In particular, from 2009 onwards, production capacity in the EU has increased markedly, primarily as a result of investments in renewables as opposed to conventional technologies. On the demand side, new opportunities also arise, such as heat pumps for the heating demand of households, and electrical vehicles which can potentially cover most personal transport. However, many industrial processes may also hide a large potential for "greening" production with the use of electricity and an important question is how policy makers can prompt industry to rely on electrical solutions to a larger extent and become less dependent on fossil-based energy sources. Besides direct regulation, one approach is to attempt to influence the economic incentives of firms for substituting electricity for other energy carriers: If industrial consumers react in the long run to changes in the relative price of electricity to other energy, substitution in energy consumption of environmentally friendly electricity for fossil-based energy, may be induced, for example by increasing taxes on the consumption of the latter, or reducing taxes on electricity.

This research offers an empirical investigation of industrial long-run energy demand with a focus on the propensity to substitute between electricity and other energy inputs. Using historical time series,

${ }^{1}$ See http://ec.europa.eu/economy_finance/publications/. 
covering 1966-2011, the paper presents an econometric analysis of the demand for electricity and other energy in eight different subsectors of the Danish economy. Here, other energy is an aggregate which comprises liquid fuels, non-liquid (coal and coke), gas (natural and gas works gas), district heating and biomass. Together, the subsectors account for the bulk of total industrial energy consumption and aggregate economic activity, and represent the primary -, secondary - and tertiary sectors. The Danish data are known to be of high quality and wide coverage by international standards, and hence, provide a unique opportunity for gaining detailed insights into the dynamics of energy substitution at the subsector level.

For each of the eight subsectors, electricity consumption is assumed to be jointly determined with labor, capital, material and other energy. Under simplifying assumptions this is shown to imply that longrun electricity consumption depends on the price of electricity and other energy, both relative to the prices of the remaining inputs. The same holds for other energy. Combining this with the statistical assumption that the time series data are non-stationary of the integrated type, naturally suggests a Cointegrated VAR approach (see e.g. Johansen, 1996). In particular, the present analysis is based on a partial Cointegrated VAR (conditional on heating degree days) for electricity, other energy, as well as their respective prices. $^{2}$ The null hypothesis or working hypothesis tested in this, is the composite hypothesis consisting of demand relations for electricity and other energy, parameterized as two cointegrating relations, and the exogeneity of prices.

The literature of studies of energy demand more broadly, which use cointegration techniques, is vast as witnessed, for example, by the survey in Suganthi and Samuel (2012). Nevertheless, as pointed out in Bernstein and Madlener (2015), there are surprisingly few analyses concerning the estimation of electricity demand elasticities for industrial consumers. This is particularly true when it comes to analyses of industrial subsector demand, which allow for substitution between electricity and other energy. Most of the related econometric analyses with several types of energy (in addition to electricity) are either based on macro- or aggregate industrial data (see e.g. Nasr et al., 2000; Lee and Chang, 2005; Erdogdu, 2007; Polemis, 2007; Yuan et al., 2008). On the other hand, disaggregate or subsector analyses of industrial electricity consumption, also based on cointegration, have been adopted in Fouquet et al. (1997), Galindo (2005), Zachariadis and Pashourtidou (2007) and Bernstein and Madlener (2015). However, these studies do not focus on substititution as such, and therefore do not have to model electricity jointly with the demand for other energy inputs. ${ }^{3}$ Finally, with respect to analyzing Danish time series data, and indeed also based on a Cointegrated VAR, Bentzen and Engsted (1993) should be mentioned. However, their focus is on macro level data and one energy aggregate. Altogether, in spite of a vast related literature, there is plenty of scope for contributing valuable insights into energy demand and substitution, when basing the analysis on a Cointegrated VAR for subsector data.

The present analysis shows that it is possible to empirically identify simple partial Cointegrated VARs, with two cointegrating relations, for all eight subsectors. These CVARs have cointegrating coefficient estimates which are interpretable in light of the working hypothesis. The results are obtained in reasonably well-specified models, with constant parameters (conditional on a limited number of breaks). For five large subsectors, referred to as, Agriculture, Machine- and vehicle manufacturing, Construction, Trade and Other services, the results are in general robust towards sample changes and the presence of a third cointegrating relation between relative prices. For these five sectors the estimation supports significant own-price and/or cross-price effects. An impulse-response experiment is therefore carried out for these sectors, in order to analyze the potential for environmental taxation to induce substitution of electricity

\footnotetext{
${ }^{2}$ See Johansen (1992) and Chapter 8 in Johansen (1996).

${ }^{3}$ To some extent Zachariadis and Pashourtidou (2007) is an exception, in that, in they initially seem to have considered cross-price effects. However, they find insignificance and therefore do not focus on this in the remainder of their paper.
} 


\footnotetext{
${ }^{4}$ This has been pointed out previously. See e.g. Pesaran et al. (1998), and more recently Bernstein and Madlener (2015).

${ }^{5}$ An immense number of analyses of energy consumption at the more aggregate (macro) level, have accumulated over the years. See e.g. the surveys, Payne (2010) and Ozturk (2010). However, for the most part this literature is concerned with the interdependence between total energy consumption and aggregate economic activity (GDP), and not substitution between energy types.

${ }^{6}$ For this purpose, work has already been done in connection with the Danish macroeconometric model, EMMA, and I therefore build on this, Møller Andersen et al. (1998).

${ }^{7}$ For an empirical analysis of the impact of changing foreign trade patterns on the energy consumption of the Danish manufacturing industries, see Klinge Jacobsen (2000)
} 
research.

\section{The Econometric framework}

\subsection{Data}

This section contains a brief introduction of the data. For a more elaborate description the reader is referred to Appendix A. The data consist of annual time series 1966-2011 from eight different subsectors of the Danish economy. ${ }^{8}$ Together these account for the bulk of total industrial energy consumption and economic activity, and represent the primary -, secondary - and tertiary sectors (see the appendix). Each of the eight subsectors are aggregates of national accounts industries. As mentioned, these aggregations attempt to group the national accounts industry categories into relatively energy homogenous industries. Table 1 shows which particular national account industries are included in each of the eight subsectors.

Table 1: National accounts industries comprised in each of the eight subsectors.

\begin{tabular}{|c|c|c|c|c|}
\hline Agriculture & Food Manufacturing & Chemical Manufacturing & Machine/Vehicle Manufacturing & Other Manufacturing \\
\hline Agriculture and horticulture & Production of meat & Manufacture of basic chemicals & Manufact. of fabricated metal & Manufacture of textiles \\
\hline \multirow[t]{10}{*}{ Forestry } & Processing of fish & Manufact. of paints, soap etc. & Manufact. of computers, etc. & Manufacture of wearing apparel \\
\hline & Manufacture of dairy products & Pharmaceuticals & Manufact. of other electronics & Manufacture of footwear etc. \\
\hline & Manufacture of bakery products & Manufacture of rubber etc. & Manufacture of motors, etc. & Manufacture of wood etc. \\
\hline & Other manufacture of food & & Manufacture of wires, cables & Manufacture of paper etc. \\
\hline & Manufacture of beverages & & Manuf.of household appl. etc. & Printing etc. \\
\hline & Manufact. of tobacco products & & Manufacture of engines etc. & Manufacture of concrete etc. \\
\hline & & & Manufacture of other machinery & Manufacture of furniture \\
\hline & & & Manuf. of motor vehicles etc. & Manufact. of med. instruments \\
\hline & & & Mf. of ships, transport equip. & Manufacture of toys, etc. \\
\hline & & & & Repair, inst. of machinery etc. \\
\hline Construction & Trade & Other services & Other services (cont.) & \\
\hline Construction of new buildings & Sale of motor vehicles & Sewerage & Rental and leasing activities & \\
\hline Civil engeneering & Repair etc. of motor veh. etc. & Waste and materials & Employment activities & \\
\hline Professional repair and maint. & Wholesale & Publishing & Travel agent activities & \\
\hline \multirow[t]{16}{*}{ Own-account repair and maint. } & Retail sale & Publishing,computer games etc. & Security and investigation & \\
\hline & & Motion picture, tv and sound & Services to buildings,cleaning & \\
\hline & & Radio, television broadcasting & Other business services & \\
\hline & & Telecommunications & Rescue service ect. (market) & \\
\hline & & Information technology service & Adult-,other education(market) & \\
\hline & & Information service activities & Medical and dental practice & \\
\hline & & Buying, selling of real estate & Theatres, concerts, and arts & \\
\hline & & Renting, non-resid. Buildings & Libraries, museums (market) & \\
\hline & & Legal activities & Gambling and betting & \\
\hline & & Accounting and bookkeeping & Sports activities (market) & \\
\hline & & Business consultancy & Amusement and recreation & \\
\hline & & Architecture and engineering & Activities of membership org. & \\
\hline & & Research and developm.(market) & Repair of personal goods & \\
\hline & & Advertising, market research & Other personal services & \\
\hline & & Other technical business serv. & Households as employers & \\
\hline & & Veterinary activities & & \\
\hline
\end{tabular}

The subsector representing the primary sector is referred to as Agriculture and includes horticulture and forestry in addition to agriculture. The energy intensity is high in this subsector which accounts for almost all energy consumption of the primary sector. The subsectors of the secondary sector comprise, Food manufacturing, Chemical manufacturing, Machine- and vehicle manufacturing, Other manufacturing and Construction. Together these subsectors account for about $80 \%$ of all energy consumption in the secondary sector. The service sector of the economy is represented by two subsectors, referred to as Trade and Other services, of which the latter comprises a wide range of services (see Table 1). Together, Trade and Other services account for around $60 \%$ of all energy consumption in the tertiary sector.

For each subsector, the variables of interest are the following (the particular selection of variables is motivated in the next section): ${ }^{9}$ Electricity intensity, or electricity consumption per unit of output, $\frac{E_{t}}{Y_{t}}$, where $E_{t}$ is electricity consumption in gigajoule (GJ) and $Y_{t}$ is real Gross Output $\left(Y_{t}\right)$. The intensity of other energy, denoted, $\frac{O_{t}}{Y_{t}}$, which is defined analogously. The prices of electricity and other energy,

${ }^{8}$ The sample stops in 2011 as subsequently Statistics Denmark redefined some of the industry groups.

${ }^{9}$ The exact definitions of the variables are found in Appendix A. 
$P_{t}^{E}$ and $P_{t}^{O}$, respectively, stated in Danish kroner per GJ and both deflated by the GDP deflator, $P_{t}$. Heating degree days, i.e. the exogenous weather-related variable to be conditioned on.

Each of the first four panels of Figure 1 shows the time series plots for the variables in logarithms, for all eight subsectors. The sixth panel shows heating degree days (common for all subsectors) in logarithms. Figure 2 shows the corresponding first differences. The overall impression is that levels are drifting rather persistently around linear deterministic trends. In addition, level breaks appear. In general, this is most pronounced for the intensity of other energy (panel 4 in Figure 1), clearly a result of the two oil crises, and the compensating large drop in energy prices around the mid-1980s. However, level shifts and "spikes" appear also for the other variables for the various industries. These are addressed individually below. Compared to the levels in Figure 1, the first differences in Figure 2 are more stable, fluctuating around fairly constant levels, with spikes here and there, reflecting the level shifts.

Figure 1: The annual time series of the logarithmic transfomed levels for all eight subsectors.
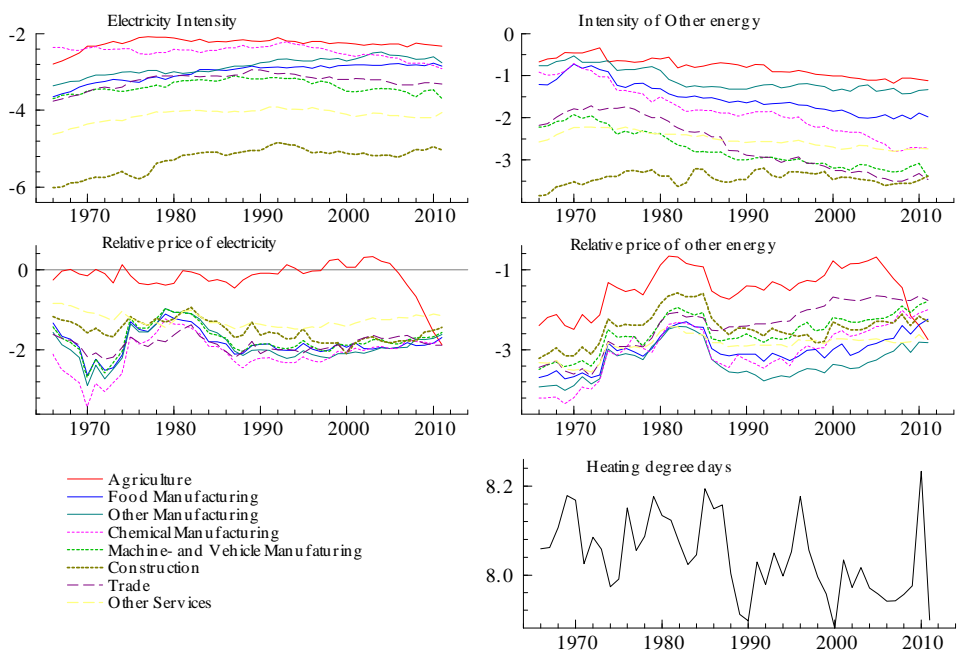

Source: Statistics Denmark and Elværksstatistikken (for heating degree days).

Figure 2: The first differences of the logarithmic transformed variables from Figure 1.
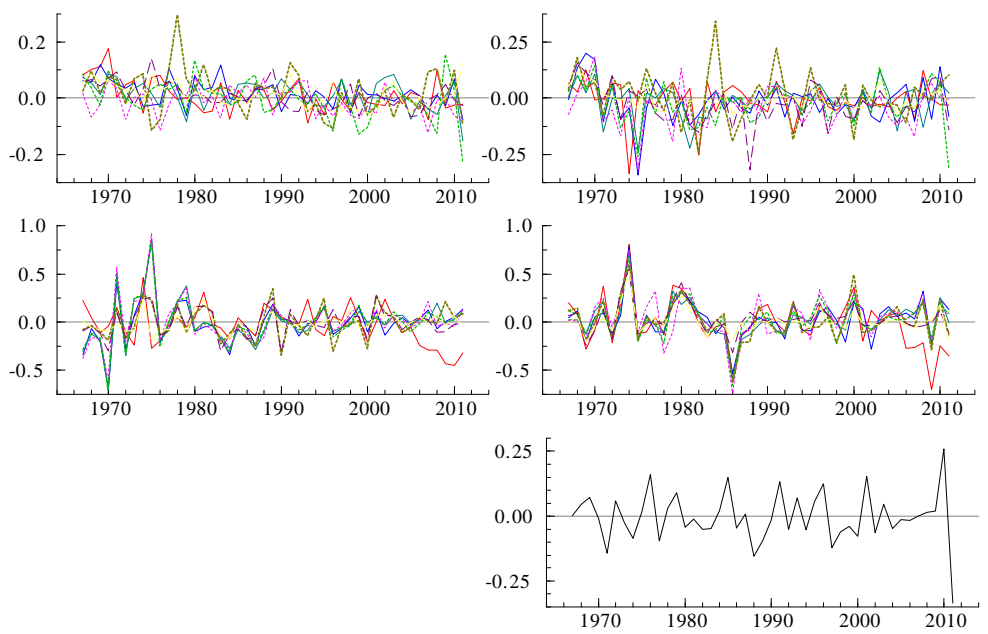
The indication of drifting levels with first differences being more stable suggests that these series can be econometrically modeled as realizations of an I(1) Cointegrated VAR process (see Section 2.3).

\subsection{A behavioral working hypothesis for the long-run dynamics}

The purpose is now to briefly sketch a working hypothesis which states how the variables are expected to relate in a steady state. In short, this simply consists of two demand relations, one for electricity and one for other energy, and the assumption that prices are exogenous to the individual subsector. As explained below, having a working hypothesis provides a point of departure for imposing just-identifying restrictions in the initial part of the estimation, thereby facilitating the identification of the actual longrun dynamics of the data.

As pointed out in Berndt and Wood (1975) energy demand is a derived input demand in a similar fashion as the demand for intermediate material, labour and capital. Assuming that firms minimize costs, given their level of output and the prices of all inputs, the demand relations for electricity and other energy can be viewed as the solutions of the corresponding sufficient first order conditions. The form of this equation system and hence the properties of its solutions will depend on the functional form of the underlying production function. As a simple and tractable approximation, assume, for (subsector) Gross Output, a nested constant-elasticity-of-substitution (CES) production function with constant returns to scale (CRS) and with inputs, capital, labor, material, electricity and other energy. ${ }^{10}$ If this is coupled with the approximation that there is no substitution towards material, it follows that the demand for both electricity and other energy, per output unit, will depend on their relative prices, relative to a price CES-aggregate with respect to capital, labour and energy. In the data analysis below, the latter is approximated by the Gross Domestic Product deflator at factor cost, $P_{t} \cdot{ }^{11}$

In addition to energy demand as arising from the production process, in order to increase estimation efficiency and avoid potential omitted variable biases, it is necessary to control for other influences. In particular, for energy demand heating degree days could be important. Apriori this is expected to hold primarily for other energy and not electricity. However, as one can simply test whether or not the latter could be the case, heating degree days are allowed to enter the electricity relation as well.

Assuming a steady state for the (trend-adjusted) energy variables given the price variables (and heating degree days) one can make a log-linear approximation of such a conditional system (around the steady state), to obtain long-run demand relations in logarithms. This leads to the long-run equations,

$$
\begin{aligned}
& e y_{t}=\theta_{e, t}+\gamma_{e} p r_{t}^{e}+\delta_{e} p r_{t}^{o}+\eta_{e} h_{t}, \\
& o y_{t}=\theta_{o, t}+\gamma_{o} p r_{t}^{e}+\delta_{o} p r_{t}^{o}+\eta_{o} h_{t},
\end{aligned}
$$

where $e y_{t} \equiv \ln \left(E_{t}\right)-\ln \left(Y_{t}\right)$, oyt $\equiv \ln \left(O_{t}\right)-\ln \left(Y_{t}\right), p r_{t}^{e} \equiv \ln \left(P_{t}^{E}\right)-\ln \left(P_{t}\right), p r_{t}^{o} \equiv \ln \left(P_{t}^{O}\right)-\ln \left(P_{t}\right)$ and $h_{t} \equiv \ln \left(H_{t}\right), H_{t}$ being heating degree days. ${ }^{12}$ Although in the estimation below, the parameters of (1) and (2) vary unrestricted, a reasonable working hypothesis suggests that own-price coefficients, $\gamma_{e}$ and $\delta_{o}$,

\footnotetext{
${ }^{10}$ Such production function seems reasonable as a working hypothesis when analyzing time series such as the Danish. In particular, it has been used in the large-scale macroeconometric model ADAM of the Danish economy (Knudsen and Smidt, 1994). With regard to CRS, also note that in the context of several inputs considered, i.e. material, energy, capital and labor, the assumption of CRS seems reasonable. This is relative to more stylized or text book-like production functions which typically have only two inputs, capital and labor. Finally, an output elasticity of unity (as is implied by CRS) has been found previously in the literature. Although dated, see Bentzen and Engsted (1993) and references therein.

${ }^{11}$ See Knudsen and Smidt (1994) (in Danish), and note also that the variable for economic activity is Gross Output (e.g. analyzed in Berndt and Wood, 1975) whereas it is the deflator with respect to Gross Domestic Product at factor cost, $P_{t}$, that is used in the expression for the relative prices of electricity and other energy.

${ }^{12}$ Acknowledging the presence of the other (non-energy) inputs and adhering to the above assumptions, the equations (1) and (2) should, strictly speaking, be accompanied by a third equation for an aggregate for capital, labor and total energy. However, it can be shown that due to Slutsky symmetry and price homogeneity, which follow from the above cost minimization problem, and the fact that the share of energy of total costs is rather limited for most industries, this equation can in practice be ignored in the estimation without any significant loss of information.
} 
are negative, whereas cross-price coefficients, $\delta_{e}$ and $\gamma_{o}$, are positive. The $\theta_{\cdot, t}$ are deterministic functions of time, and include constants, trend terms and dummy variables. Trend terms describe the underlying smooth component of the evolution of energy intensities. If negative this supposedly reflects long-term energy savings resulting from technological progress and economies of scale. Dummy variables, on the other hand, are more likely to proxy the influence from exogenous extraordinary factors, e.g. energy crises and economic policy interventions etc. (see below).

To sum up, the working hypothesis consists of the two long-run relations (1) and (2), together with the hypotheses of negative own-price coefficients, positive cross-price coefficients, and exogenous relative input prices. In Section 2.3, when the statistical model has been introduced, it is explained what this hypothesis implies in terms of testable restrictions.

\subsection{The statistical model}

In the statistical model it is assumed that the variables, $p r_{t}^{e}, p r_{t}^{o}, e y_{t}$, and $o y_{t}$ are determined jointly in a system of equations. That is, they are treated as endogenous from the outset. Heating degree days, $h_{t}$, is treated as exogenous, i.e. influences this system but is itself determined by factors outside this system. As mentioned, the working hypothesis imposes further exogeneity, so that in addition to $h_{t}$ one could also condition on $p r_{t}^{e}$ and $p r_{t}^{o}$. However, the exogeneity of these variables is not as obvious as that of $h_{t}$, and as a result it is preferred to test this in the partial model of $p r_{t}^{e}, p r_{t}^{o}, e y_{t}$, and oyt, conditional on $h_{t}$. The statistical model, in which the long-run relations (1) and (2), can be tested as parametric restrictions, is therefore a partial or conditional CVAR model for $\left(p r_{t}^{e}, p r_{t}^{o}, e y_{t}, o y_{t}\right)$, which conditions on $h_{t}$. The formal statistical argument for applying this, is that exogeneity, in the above sense, implies that $h_{t}$ is (strongly and thus) weakly exogenous for the cointegrating matrix (i.e. $\beta$ below), which includes the main parameters of interest (see e.g. Johansen, 1992). As shown ibid, it follows that efficient estimation of $\beta$ can then be obtained based on the partial model, which is more parsimonious.

Before stating the partial model, denote the full variable vector as $x_{t}^{\prime}=\left(p r_{t}^{e}, p r_{t}^{o}, e y_{t}, o y_{t}, h_{t}\right)$, and partition this into $x_{t}^{\prime}=\left(z_{t}^{\prime}, h_{t}\right)$ where $z_{t}^{\prime} \equiv\left(p r_{t}^{e}, p r_{t}^{o}, e y_{t}, o y_{t}\right)$. Assume that, conditional on the past, $x_{t}$ has a joint Gaussian distribution, i.i. $N_{5}(0, \Omega)$, with $\Omega$ positive definite. Further, suppose that the process of $x_{t}$ given the past has the $\operatorname{VAR}(2)$ representation, ${ }^{13}$

$$
\Delta x_{t}=\Pi x_{t-1}+\Gamma_{1} \Delta x_{t-1}+\Phi \mathcal{D}_{t}+\varepsilon_{t},
$$

for $t=1,2, . ., T$, and which has been written in the Error-Correction-Mechanism (ECM) form and where $\varepsilon_{t} \sim$ i.i. $N_{5}(0, \Omega)$ and $\mathcal{D}_{t}$ is a $d \times 1$ vector of deterministic components (dummy variables, trend, constant). It is assumed that the characteristic roots, $\lambda \in \mathbb{C}$, always obey either $\lambda=1$ or $|\lambda|>1$, where $|\cdot|$ denotes the modulus. Thus, if there are no roots at 1 , or equivalently, $\operatorname{det}(\Pi) \neq 0$, then $x_{t}$ is stationary. ${ }^{14}$ In contrast, if at least one real-valued unit root exists (i.e. $\lambda=1$ ) or equivalently $\operatorname{det}(\Pi)=0$, then $x_{t}$ is non-stationary. In other words, $\Pi$ has reduced rank, $r<5$, which is parameterized as a non-linear restriction on $\Pi$ in (3), that is,

$$
\Pi=\alpha \beta^{\prime},
$$

where the matrices $\alpha$ and $\beta$ are $5 \times r$ of rank $r$. If furthermore, $\operatorname{det}\left(\alpha_{\perp}^{\prime}\left(I-\Gamma_{1}\right) \beta_{\perp}\right) \neq 0$, where $\alpha_{\perp}$ and $\beta_{\perp}$ (both $5 \times 5-r$ ) denote the orthogonal complements of $\alpha$ and $\beta$, it follows from Theorem 4.2 in Johansen (1996) that $x_{t}$ is I(1) and follows a CVAR which, for $0<r \leq 5$, has $r$ cointegration relations given by the columns in $\beta$. This is assumed for the present analysis, meaning that only $\mathrm{I}(1)$ cointegration

\footnotetext{
${ }^{13}$ For all VAR models estimated in Section 3, two lags were sufficient.

${ }^{14}$ I.e."asymptotically stationary" in the sense that it can be made stationary by a suitable choice of initial values see (see Johansen, 1996, p. 15, for example).
} 
is considered. ${ }^{15}$

Using the above partitioning, $\left(z_{t}^{\prime}, h_{t}\right)^{\prime}$, and an corresponding partitioning of the parameters, equation (3), with (4) imposed, can be written as,

$$
\left(\begin{array}{c}
\Delta z_{t} \\
\Delta h_{t}
\end{array}\right)=\left(\begin{array}{c}
\alpha_{z} \\
\alpha_{h}
\end{array}\right) \beta^{\prime} x_{t-1}+\left(\begin{array}{c}
\Gamma_{z, 1} \\
\Gamma_{h, 1}
\end{array}\right) \Delta x_{t-1}+\left(\begin{array}{c}
\Phi_{z} \\
\Phi_{h}
\end{array}\right) \mathcal{D}_{t}+\left(\begin{array}{c}
\varepsilon_{z, t} \\
\varepsilon_{h, t}
\end{array}\right)
$$

where $\alpha_{z}$ is $4 \times r, \alpha_{h}$ is $1 \times r, \Gamma_{z, 1}$ is $4 \times 5, \Gamma_{h, 1}$ is $1 \times 5, \Phi_{z}$ is $4 \times d, \Phi_{h}$ is $1 \times d$ and with the covariance matrix decomposed as, $\Omega=\left(\Omega_{i, j}\right)$ for $i=z, h$ and $j=z, h$ where $\Omega_{z z}$ is $4 \times 4, \Omega_{h z}$ is $1 \times 4, \Omega_{z h}$ is $4 \times 1$, $\Omega_{h h}$ is $1 \times 1$. As mentioned, imposing weak exogeneity of $h_{t}$, implying $\alpha_{h}=0$, efficient inference about $\beta$ may then be conducted based on the conditional model of $\Delta z_{t}$ given $\Delta h_{t}$ and the past, given by,

$$
\Delta z_{t}=\theta \Delta h_{t}+\alpha_{z} \beta^{\prime} x_{t-1}+\Theta_{z} \Delta x_{t-1}+\Psi_{z} \mathcal{D}_{t}+e_{z, t},
$$

where $\theta \equiv \Omega_{z h} \Omega_{h h}^{-1}, \Theta_{z} \equiv \Gamma_{z, 1}-\theta \Gamma_{h, 1}, \Psi_{z} \equiv \Phi_{z}-\theta \Phi_{h}, e_{z, t} \equiv \varepsilon_{z, t}-\theta \varepsilon_{h, t}$ where $e_{z, t} \sim i . i . N_{4}\left(0, \Omega_{z}\right)$ with $\Omega_{z} \equiv \Omega_{z z}+\Omega_{z h} \Omega_{h h}^{-1} \Omega_{h z}$ and uncorrelated with $\varepsilon_{h, t}$.

In terms of (6), the working hypothesis implies, two cointegrating relations ( $\beta$ is $5 \times 2$ of rank 2 ), which are restricted and normalized corresponding to (1) and (2), for which the signs of the estimated cointegration coefficients are as expected, and that the two first rows of $\alpha_{z}$, corresponding to $p_{t}^{e}$ and $\operatorname{pr}_{t}^{o}$, contain zeros only. The working hypothesis thus amounts to a submodel of (6) and is tested as such.

For reliable statistical inference on this submodel, a well-specified or statistically adequate unrestricted partial VAR is first formulated. This is simply a partial VAR model like (6) including the above error term assumptions but where no restrictions have been imposed, in particular, whether the matrix in front of $x_{t-1}$ equals $\alpha_{z} \beta^{\prime}$. That the model is well-specified implies here that constant parameters can be assumed and that, based on the residual analysis, it is reasonable to assume that the errors do not exhibit auto-correlation, non-normality or heteroscedasticity. Statistical adequacy is assessed by residual-based multivariate misspecification tests (see below). The most important assumption is that of no autocorrelation since the presence of correlated errors implies inconsistent estimators. Once statistical adequacy of the unrestricted partial VAR has been established, one can proceed to test the hypothesis of $r=2$ based on the trace test (multivariate unit root test) and other criteria, as described below. Given this, $\alpha_{z}$ and $\beta$, under the working hypothesis, can be estimated as described in Doornik (1995).

Estimation requires identification and the working hypothesis imposes a single zero restriction on each of the two cointegrating relations, which fulfill the rank conditions for generic identification, see Chapter 5 in Johansen (1996). Hence, $r$ times $r-1$ just identifying restrictions are imposed on the cointegrating space, implying that it is possible to estimate the two long-run relations and obtain standard errors for the long-run coefficients. The latter can then be used to assess the significance of (or lack of) the cointegrating coefficients and thus reduce the model accordingly by excluding insignificant coefficients. In this way the present econometric approach is a compromise between a priori information, the working hypothesis, and data-led analysis (well-specified unrestricted VAR and model reductions based on insignificance).

In practice, obtaining a well-specified model requires taking account of influential events that the model is not intended to explain and that may obscure and bias the estimation of the structural relations. This is usually done by introducing level shift dummies and/or exclude extraordinary time periods. Here, it was necessary to include level shift dummies, i.e. with the form $(0, . ., 0,0,1,1,1,1,1,1, \ldots, 1)$. The coefficients of the levels of these shift dummies are restricted such that breaks in the level of the variables are allowed not to cancel in the cointegrating relations and at the same time do not cumulate into broken linear

${ }^{15}$ If $\operatorname{det}\left(\alpha_{\perp}^{\prime}\left(I-\Gamma_{1}\right) \beta_{\perp}\right)=0$ and a further full rank condition holds (see Johansen, 1996, p. 58), $x_{t}$ is I(2). 
trends. If the breaks cancel, which is assessed by testing a zero restriction on the respective cointegration coefficient, the shift dummy is excluded from the cointegration relations, and an unrestricted impulse dummy, i.e. with the form $(0, . ., 0,0,1,0,0,0,0,0, \ldots, 0)$, is included instead (see e.g. Juselius, 2006). When including the level of a shift dummy (with the restriction on its coefficients, cf. the above) its first difference (from lag 0 to $k-1$ ) enters unrestricted. ${ }^{16}$ Trends (linear deterministic) enter the model in the same fashion. Hence, trends are allowed in the variables, and may not cancel in the cointegrating relations, and at the same time these trends are restricted such that quadratic trends are avoided. Finally, to take account of more temporary outliers, dummies with the form $(0, . ., 0,0,1,-1,0,0,0,0, \ldots, 0)$ were included.

\section{Estimation results for the eight subsectors}

With the working hypothesis as the point of departure, the purpose is now to estimate cointegrating relations between the variables, $e y_{t}, o y_{t}, p r_{t}^{e}$, and $p r_{t}^{o}$, given $h_{t}$, for each of the eight subsectors.

The specifications of the unrestricted partial VAR models for each subsector are given in Table 2. The table lists the lag length (either 1 or 2 ) and the years for the various dummy variables, which were necessary to obtain a well-specified unrestricted model with constant parameters for each subsector. It appears from the table that in most cases the years for the breaks coincide with major exogenous events. For example, breaks were needed for 1973-74 and 1978-79 to take account of the two major energy crises, and the large drop in energy prices and contractionary fiscal policy around 1985-86, also had to be conditioned on. Note the different timing across the eight subsectors, associated with some of the breaks, which may reflect that a given shock impacts on the different industries in a staggered way. The estimation results with respect to these breaks and trends constitute an interesting by-product of the analysis and they are further described in Appendix C.

The multivariate misspecification tests for statistical adequacy are reported in Appendix B. It appears that the hypothesis of no autocorrelation in the errors is accepted at the $5 \%$ level for all subsectors and in most cases with a relatively high p-value (reported in the square bracket). The test for normality and heteroscedasticity are reported in the next two lines. In five out of the eight cases normality can be accepted at the $1 \%$ level. In the cases of rejection, what drives the test away from normality is excess kurtosis, but otherwise the residual distributions were relatively symmetrical. As a result nonnormality seems not to be critical here. In six out of the eight cases it was possible to compute the misspecification test for heteroscedasticity. Again the absence of heteroscedasticity was accepted at the $1 \%$ level in all six cases. Note that, for Chemical- and Other manufacturing, the model has 2 lags and three breaks plus a transitory dummy, making the number of parameters relative to observations relatively large thereby prohibiting the computation. In any case, the existence of (moderate) heteroscedasticity is usually not crucial for the long-run estimates. In addition to the error term assumptions, as assessed by these misspecification tests, the assumption of constant parameters was also assessed in connection with specifying the models cf. Table 2, and constancy could be accepted for the unrestricted partial VARs. This assumption is further assessed, by recursive estimation, for the cointegrated models below.

\footnotetext{
${ }^{16} \mathrm{By}$ treating the level like this, similarity in the trace test is obtained, as the effect on the variables from this deterministic term is the same under the null and the alternative (see Nielsen and Rahbek, 2000).
} 
Table 2: Specification information for the partial unrestricted VARs for each industry. Lag length and years for breaks, impulse- and transitory dummies.

\begin{tabular}{l|c|l|l}
\hline \hline & \multicolumn{2}{|c}{ Dummy variables } \\
\hline Agriculture & 1 & $1969,1978,1986$ & Impulse and transitory: \\
Manufacturing: & & & \\
Food & 2 & 1969,1979 & \\
Chemical & 2 & $1975,1978,1989$ & Transitory in 1970 \\
Machine- and vehicle & 1 & $1969,1986,2010$ & \\
Other & 2 & $1974,1985,2009$ & Transitory in 1970 \\
Construction & 1 & 1995,2000 & Impulses in 1969, 1987 \\
Services: & & & \\
Trade & 1 & 1974 & Impulse in 1988 \\
Other & 1 & $1970,1974,1979,2009$ & \\
\hline \hline
\end{tabular}

Altogether, given the misspecification tests in Appendix B, all models seem reasonably well-specified. Given this one can turn to the cointegrating analysis, that is the statistical inference about the cointegrating rank. Even though the working hypothesis implies $r=2$, it should be checked that this restriction is not completely contradicting the evidence based on the unrestricted estimation. The results from applying the top-down testing procedure for the trace test, as described in Johansen (1996), are given in Table 3. The table shows the value of the rank, $r$, as suggested by the trace test. Unless this is clear-cut, in the (loose) sense that the associated p-values are far from $5 \%$ the outcome is given as an interval to indicate the uncertainty explicitly. It occurs more often than not that the results from the trace test are not sufficiently clear-cut in the sense of pointing towards one particular value of $r$. As discussed in Juselius (2006), since the choice of cointegration rank usually has influence on the subsequent inference (e.g. about the long-run relations), it is therefore important to supplement the results from the trace test and use as much other information as possible. This approach is also adopted here: In particular, based on the unrestricted model $(r=4)$ and the model with $r=3$ imposed, the modulus of the eigenvalues of the companion matrix (inverse characteristic roots), the graphs of the cointegrating relations, $\widehat{\beta}^{\prime} x_{t}$, and the significance of individual adjustment coefficients in $\widehat{\alpha}_{z}$, were all inspected. The results from considering all these pieces of information for all industries are summarized in Table 3.

Table 3: Summarizing information on the inference on the Cointegration Rank. The numbers refer to the cointegrating rank.

\begin{tabular}{l|cc|c|c}
\hline \hline \multicolumn{5}{c}{ Model aspect } \\
\hline Agriculture & $2-3$ & $2-3$ & 2 & 2 \\
Manufacturing: & & & & \\
Food & $2-3$ & $2-3$ & 2 & $2-3$ \\
Chemical & 3 & $3-4$ & $1-2$ & $2-3$ \\
Machine- and vehicle & 2 & 3 & 2 & $2-3$ \\
Other & $1-2$ & $2-3$ & $1-2$ & $2-3$ \\
Construction & 0 & 2 & $2-3$ & $2-3$ \\
Services: & & & & \\
Trade & 2 & $2-3$ & $1-2$ & $2-3$ \\
Other & $2-3$ & $2-3$ & 2 & 2 \\
\hline
\end{tabular}

Notes: In the presence of variables the asymptotic distributions of the trace test statistic are simulated in CATS in RATS.

As is often the case, the table first of all suggests that there is some uncertainty associated with 
the choice of rank. On the other hand, $r=2$ seems in general to be a reasonable point of departure, consistent with the working hypothesis. However, it is also the impression that in most cases a third cointegrating relation may exist. Therefore, as a robustness check of the cointegration estimates given $r=2$, Section 3.2 identifies and adds a third relation to assess whether the estimates of the two first relations are sensitive to this.

\subsection{Estimation results by subsector}

Having established that the models are reasonably well-specified and that the choice of two cointegrating relations is clearly consistent with the evidence, this section describes the estimation results for $\alpha_{z}$ and $\beta$ given $r=2$. In the initial estimations the restrictions implied by the working hypothesis are imposed. That is, as described above, the zero rows in $\alpha_{z}$ and the just-identifying restrictions on $\beta$ as implied by (1) and (2). Subsequently, insignificant regressors are removed from the long-run relations. The p-value below corresponds to the resulting restricted partial CVAR against a partial CVAR with $r=2$, as the only restriction imposed. Henceforth, this is referred to as the p-value of the overall restriction. Since the method is the same for all eight subsectors most space for explanations has been devoted in connection with describing the first subsector, Agriculture.

Agriculture: The estimates of the restricted versions of $\alpha_{z}$ and $\beta$ in (6) are given in the first part of Table 4 . Note that the $\widehat{\beta}$ matrix (or its two columns transposed, $\widehat{\beta}_{1}^{\prime}$ and $\widehat{\beta}_{2}^{\prime}$ ) has been augmented with the deterministic components. The estimates of the deterministic components for all subsectors are analyzed in Section $\mathrm{C}$ in the appendix. It is noted from the table that the overall restriction imposed by the working hypothesis is accepted with relatively high p-value, 0.43 . The signs and significance of the own and cross-price coefficients are as expected, recalling that the cointegration relation by convention is written in the deviation form, so that the sign is reversed compared to (1) and (2). The estimates in $\widehat{\beta}_{1}^{\prime}$, corresponding to electricity demand, thus suggest that the long-run own-price coefficient is 0.15 (or $15 \%$ ), whereas the cross-price coefficient is about the same magnitude 0.18 , both significant with absolute t-values, 2.68 and 3.85, respectively. For the demand relation for other energy the own-price coefficient is also significant and of similar magnitude (0.14), whereas the cross-price coefficient is somewhat lower, 0.06 , and with a relatively low t-value $(-1.51)$. In fact the latter could be restricted to zero, but since this did not change any of the obtained conclusions and since the sign is as expected, it was chosen to let $p r_{t}^{e}$ remain in the demand relation for other energy.

Note that, the term, "coefficient" as opposed to "long-run elasticity" or even "long-run effect", is used. This is to stress that in general the cointegrating coefficients cannot be interpreted as such. ${ }^{17}$ Instead, the notions of long-run elasticities and long-run effects are defined explicitly in the context of the impulse-response experiment in Section 4.

The heating degree days estimate suggests that more heating degree days in a year will increase electricity demand. Note that, this is borderline insignificant $(t=-1.69)$ and can be removed although this does not change the obtained conclusions. Since the sign is as expected, it was chosen to let $h_{t}$ remain in the electricity relation.

Turning to the adjustment matrix, $\widehat{\alpha}_{z}$, the last two rows show that both $e y_{t}$ and $o y_{t}$ adjust towards equilibrium whenever pushed away from this. In particular, electricity consumption adjusts downwards if above the long-run demand (and vice versa), cf. the negative adjustment coefficient, -0.44 , which is highly significant $(\mathrm{t}=-8.41)$. For other energy the corresponding numbers are, -0.87 and -6.38 , respectively. Finally, note that the first two rows of the adjustment matrix, $\alpha_{z}$, contain zeros only consistent with the exogeneity of the relative input prices as implied by the working hypothesis.

\footnotetext{
${ }^{17}$ See Johansen (2005).
} 
Food manufacturing: The estimation results for this subsector are given the second part of Table 4 . The p-value for the overall restriction is $25 \%$. Exogeneity of the relative input prices and significant error correction of both energy intensities are also supported. However, with the exception of the cross-price coefficient with respect to electricity in the second relation, the cointegrating coefficients corresponding to the relative input prices were all insignificant and could be restricted to zero, suggesting that substititution in this subsector is negligible. The estimated cross-price coefficient with respect to electricity in the second relation, i.e. $\gamma_{o}$ in terms of (2) is 0.26 but has the opposite sign of what is expected. Finally, note that heating degree days could be excluded from both long-run relations.

Chemical manufacturing: For this subsector the p-value for the overall restriction is as high as $64 \%$. As with food manufacturing exogeneity of the relative input prices and significant error correction of both energy intensities were supported, whereas the only price coefficient that is significant is the ownprice coefficient of electricity, which has the expected sign. The significant positive estimate of heating degree days in the second relation reflects that the heating demand.

Machine- and vehicle manufacturing: The p-value for the overall restriction is $35 \%$ and there is evidence consistent with cross-price effects. However, although the both intensities error correct when their respective levels deviate from their long-run values only the relative price of other energy can be assumed to be exogenous. In other words, there seems to be some adjustment in the relative price of electricity to deviations in both intensities from their long-run relations. This adjustment may reflect general equilibrium effects between the two prices, and/or that the price-taking assumption is not sufficiently realistic. The heating degree days estimates in $\widehat{\beta}$ suggests that more heating degree days in a year will increase electricity demand.

Other manufacturing: For this subsector the p-value for the overall restriction is 14\%. The crossprice effects are insignificant for this subsector but own-price coefficients for both electricity and other energy are significant and have the expected signs. Exogeneity of the relative input prices and significant error correction of both energy intensities are also supported. As expected, the heating degree days coefficient is significant and positive in the second relation.

Construction: For Construction the p-value for the overall restriction is as high as $95 \%$. With the exception of some significant adjustment of the relative electricity price when electricity consumption per unit of output is above its long-run value the working hypothesis as a whole is supported. In particular, in addition to the own-price coefficients, cross-price coefficients, with the expected sign and of some magnitude, suggest that changes in relative energy prices induce energy substitution for this subsector. Finally, note that heating degree days could be excluded from both long-run relations.

Trade: The p-value for the overall restriction imposed by the working hypothesis is $37 \%$. Exogeneity of the relative input prices and significant error correction of both energy intensities are also supported. With the exception of a zero cross-price coefficient in the electricity relation the remaining price coefficients are significant and have the expected signs. With respect to heating degree days, note that the borderline insignificance in the first relation could be restricted to zero without affecting the conclusions and that the positive coefficient in the relation for other energy most likely reflect heating demand.

Other services: For this large aggregate of service industries the p-value for the overall restriction is as high as $81 \%$. The estimation results suggest exogeneity of the relative input prices and significant error correction and for electricity the cointegrating coefficients are in accordance with the working hypothesis, i.e. a negative own-price coefficient and a positive cross-price coefficient, both significant. The relation for other energy seems to be a simple heating demand relations with no price effects. ${ }^{18}$

\footnotetext{
${ }^{18}$ The borderline insignificant adjustment coefficient in $\widehat{\alpha}_{z}(0.15, \mathrm{t}=-1.39)$ could be restricted to zero but this did not change the long-run relations significantly.
} 
Table 4: Testing the working hypothesis: The table reports the estimates of the restricted $\alpha_{z}$ and $\beta$, given $r=2$. The restrictions implied by the working hypothesis were first imposed and then insignificant regressors were removed from the relations. If the initial restictions are rejected they have been relaxed. The $p$-value corresponds to the resulting restricted partial CVAR against a partial CVAR with $r=2$, as the only restriction imposed.

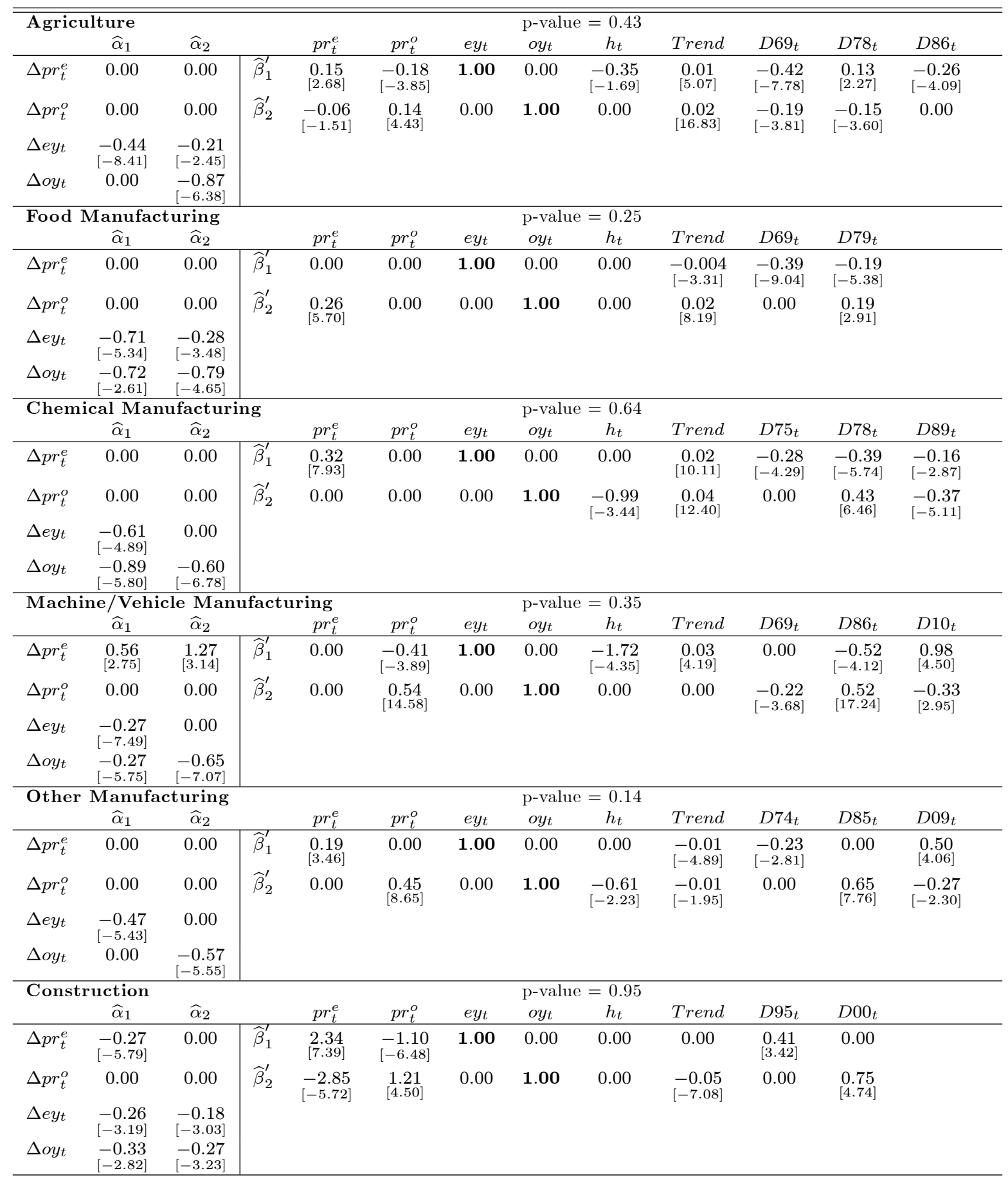


Table 4 (continued)

\begin{tabular}{|c|c|c|c|c|c|c|c|c|c|c|c|c|c|}
\hline \multirow[t]{2}{*}{ Trade } & \multicolumn{13}{|c|}{ p-value $=0.37$} \\
\hline & $\widehat{\alpha}_{1}$ & $\widehat{\alpha}_{2}$ & & $p r_{t}^{e}$ & $p r_{t}^{o}$ & $e y_{t}$ & $o y_{t}$ & $h_{t}$ & Trend & $D 74_{t}$ & & & \\
\hline$\Delta p r_{t}^{e}$ & 0.00 & 0.00 & $\widehat{\beta}_{1}^{\prime}$ & $\begin{array}{l}0.33 \\
{[3.44]}\end{array}$ & 0.00 & 1.00 & 0.00 & $\begin{array}{l}0.47 \\
{[1.65]}\end{array}$ & $\begin{array}{c}0.01 \\
{[6.09]}\end{array}$ & $\begin{array}{l}-0.53 \\
{[-8.23]}\end{array}$ & & & \\
\hline$\Delta p r_{t}^{o}$ & 0.00 & 0.00 & $\widehat{\beta}_{2}^{\prime}$ & $\begin{array}{l}-0.57 \\
{[-2.12]}\end{array}$ & $\begin{array}{c}0.82 \\
{[8.83]}\end{array}$ & 0.00 & 1.00 & $\begin{array}{l}-1.88 \\
{[-2.57]}\end{array}$ & 0.00 & 0.00 & & & \\
\hline$\Delta e y_{t}$ & $\begin{array}{l}-0.26 \\
{[-7.81]}\end{array}$ & 0.00 & & & & & & & & & & & \\
\hline$\Delta o y_{t}$ & $\begin{array}{l}-0.21 \\
{[-3.77]}\end{array}$ & $\begin{array}{l}-0.15 \\
{[-5.82]}\end{array}$ & & & & & & & & & & & \\
\hline Other & services & & & & & & p-val & $=0.81$ & & & & & \\
\hline & $\widehat{\alpha}_{1}$ & $\widehat{\alpha}_{2}$ & & $p r_{t}^{e}$ & $p r_{t}^{o}$ & $e y_{t}$ & $o y_{t}$ & $h_{t}$ & Trend & $D 70_{t}$ & $D 79_{t}$ & $D 86_{t}$ & $D 09_{t}$ \\
\hline$\Delta p r_{t}^{e}$ & 0.00 & 0.00 & $\widehat{\beta}_{1}^{\prime}$ & $\begin{array}{c}0.53 \\
{[4.38]}\end{array}$ & $\begin{array}{l}-0.33 \\
{[-4.87]}\end{array}$ & 1.00 & 0.00 & 0.00 & $\begin{array}{l}0.01 \\
{[3.91]}\end{array}$ & $\begin{array}{l}-0.17 \\
{[-1.70]}\end{array}$ & 0.00 & $\begin{array}{l}-0.13 \\
{[-1.91]}\end{array}$ & $\begin{array}{l}-0.37 \\
{[-3.55]}\end{array}$ \\
\hline$\Delta p r_{t}^{o}$ & 0.00 & 0.00 & $\widehat{\beta}_{2}^{\prime}$ & 0.00 & 0.00 & 0.00 & 1.00 & $\begin{array}{r}-0.43 \\
{[-2.89]}\end{array}$ & $\begin{array}{c}0.01 \\
{[8.38]}\end{array}$ & $\begin{array}{l}-0.20 \\
{[-3.52]}\end{array}$ & $\begin{array}{c}0.11 \\
{[3.23]}\end{array}$ & 0.00 & $\begin{array}{l}-0.21 \\
{[-3.03]}\end{array}$ \\
\hline$\Delta e y_{t}$ & $\begin{array}{c}-0.18 \\
{[-2.20]}\end{array}$ & $\begin{array}{l}-0.15 \\
{[-1.39]}\end{array}$ & & & & & & & & & & & \\
\hline$\Delta o y_{t}$ & {$\left[\begin{array}{c}0.28 \\
{[-4.37]}\end{array}\right.$} & $\begin{array}{l}-0.58 \\
{[-7.03]}\end{array}$ & & & & & & & & & & & \\
\hline
\end{tabular}

Note: The brackets contain t-ratios and the $\widehat{\beta}$ matrix is augmented with deterministic components

In general, although not all restrictions as implied by the working hypothesis are accepted for all subsectors, the estimated models are generally well-behaved in the sense of being simple and economically interpretable.

\subsection{Assessing robustness: sample changes and cointegration rank}

In spite of reasonable statistical adequacy, economically interpretable estimation results, it remains to assess whether conclusions are robust towards changes in the choice of sample and whether the model assumption of constant parameters is reasonable. Moreover, the "empirically best" choice of the cointegration rank is often uncertain and can be crucial for the inference on cointegration relations and adjustment parameters. These aspects are investigated in detail in Appendix D and here the findings are summarized.

To assess parameter constancy and the robustness of test conclusions, i.e. with respect to the sign and significance of cointegrating estimates and the p-value of the overall restriction, towards sample changes, forward recursive estimation of CVAR models restricted as in Table 4, was performed for each subsector. As discussed in the appendix, taking into account the anticipated variability in the beginning of the forward recursive graphs (due to short-sample uncertainty), the analysis suggests that parameter constancy seems reasonable and that the overall/joint restrictions are accepted for the vast majority of subsamples. In addition, the conclusions from Table 4, with respect to significance of individual price coefficients, are rather robust. As the forward recursive analysis cannot say anything about the influence from early observations, this was complemented by an assessment of the robustness towards the exclusion of the first part of the sample. This exercise is meant only to give an rough indication and, as argued in the appendix, the full sample estimation is preferred over this. With this in mind, this exercise nevertheless suggests reasonable robustness for five out of eight subsectors, namely Agriculture, Machine- and vehicle manufacturing, Constructions, Trade and Other services.

Table 3 suggests that although two cointegrating relations is a reasonable choice for each subsector, consistent with the working hypothesis, there is some indication of an additional cointegrating relation. In Appendix D it is therefore attempted to identify an additional relation jointly with the existing restrictions on the two first cointegrating relations. The purpose is to assess the robustness of the estimates of the two existing cointegration relations towards adding a third relation and not the latter as such. Nevertheless, as argued in Appendix D this third relation can be interpreted as capturing the 
co-movement of electricity prices and the price level of other energy. This co-movement most likely results since some of the components of Other energy, primarily coal but also oil, in particular, have been used as inputs into electricity production. Hence, the third relation is common for all eight subsectors. Table D.1 in Appendix D summarizes the estimates of the price coefficients from the first two cointegrating relations (the existing ones from Table 4), when the third relation is added. In comparison to Table 4, the table shows that in five out of the eight cases the estimated own and cross-price coefficients in the first two cointegrating relations are approximately unchanged with respect to sign, significance and magnitude. The most important exception, which relates to the electricity relation, is that for Agriculture, for which both own and cross-price coefficients become insignificant (and are therefore restricted to zero). Also, for Machine- and vehicle manufacturing there is some change in magnitudes, in that the estimated cross-price coefficient changes from 0.41 to 1.73 , albeit sign and significance are robust. For Construction the lack of robustness concerns the relation for other energy. Hence, also in this respect the overall picture clearly supports the robustness of the obtained results.

\section{The potential for environmental taxation - impulse-response analysis}

As it appears from Section 3.2, the analysis in Appendix D suggests that the estimation results for Agriculture, Machine- and vehicle manufacturing, Construction, Trade and Other services are robust. This is with respect to sample changes and, with the exception of Agriculture, towards the presence of a third cointegrating relation. Moreover, for these subsectors own-price and/or cross-price coefficients suggest that, in the long run, the input mix of electricity and other energy will change in response to a change in their relative price. For these five subsectors the purpose is now to throw light on the longrun potential for taxation to move energy consumption away from other energy and towards the more environmental friendly electricity. This can be done by using the estimated CVAR models from Section 3 to conduct a hypothetical experiment based on impulse-response functions. In general, these functions provide a complete characterization of the full dynamic adjustment (i.e. both short- and long-run effects) for all variables in the system when changing some variables.

In the recent years there has been an active debate on the Danish energy and environmental tax policy. In particular, in connection with the Growth Package 2014, it was suggested that the Public Service Obligation (PSO) tariff (on electricity use) paid by Danish enterprises should be lowered, in order to improve their international competitiveness. The PSO is a tariff on the electricity consumption by businesses and households and it is used to finance the support of initiatives within renewable energy. More recently, in the spring 2016 the Danish government proposed to abolish the PSO tax altogether, based on the same arguments. ${ }^{19}$ In spite of being a simplified analysis the impulse-response experiment below can to some extent throw some light on the potential consequences for industrial energy consumption (and thus tax revenues) of removing the PSO and increasing taxes on the consumption of other energy to compensate the lost revenues.

The impulse-response experiment illustrates the long-run effects on the demand for electricity and other energy from raising the price of other energy by $25 \%$ while at the same time lowering the price of electricity, by $25 \%$ in the long run. ${ }^{20}$ The experiment can thus be regarded as describing the longrun effects on the energy consumption mix of a simple tax reform which implies lower electricity taxes while increased taxation of other energy. The assumption of a $25 \%$ reduction in electricity prices is

\footnotetext{
${ }^{19}$ The PSO was introduced in 1998 in connection with the liberalization of electricity markets and has had its current form since 2005. It is set quarterly by the state-owned Danish national TSO, Energinet.dk, and is primarily used for ensuring a minimum price to producers of renewable electricity and to small CHPs. See e.g. www.energinet.dk.

${ }^{20}$ As usual, since all variables are in logarithmic form, all percentage changes both the impulses $( \pm 25 \%)$ and the responses are approximations.
} 
inspired by the abolition of the PSO tariff, but it should be emphasized that the experiment primarily serves as a "benchmark analysis" quantifying the dynamic responses (in particular the long run effects) of taxation. ${ }^{21}$ This may nevertheless serve as a point of departure for more realistic and applicable analyses, which preferably should split up other energy into its subcomponents and accordingly apply different tax rates for each of these. Moreover, budget balancing could be imposed, so that the revenues lost from removing taxation on electricity are matched by those collected from the extra tax on other energy. In addition legislative aspects, other governmental budget restrictions and political constraints, tax incidence across the subsectors etc. would have to be taken into account, complicating the analysis. This is therefore best left for a separate paper which may use the present work as a building block.

Although one could consider the impulse-response analysis for the model with three cointegration relations, it makes more sense to base the computations on the models from Table 4 , with $r=2$. This is because the third relation is a relation for the level of electricity prices, which, together with the exogeneity of $p r^{o}$, shows how this is driven by the price of other energy, supposedly reflecting that higher prices of coal (and oil for the earlier part of the sample) imply higher costs for power plants (cf. the discussion above). Since the purpose of taxation in the present context is to induce substitution from the use of other energy towards electricity in the industries, the relevant type of tax, should preferably be levied on the consumption of industries and not on power plants. Hence, by basing the impulse-response experiment on the models as estimated in Table 4 which have $r=2$, the relevant picture of the dynamic effects of taxation is obtained.

The computations of the impulse-response functions are based on the estimated CVAR models which are in their reduced form. This is possible because the reduced form errors can reasonably be assumed to be uncorrelated, with the exception of one correlation between the two price errors for Agriculture. In particular, correlations between residuals were in general low, and the moderate significance (compared to their approximate critical values $\pm 2 / \sqrt{T}=0.3$ ) of some correlations was driven by only one or two observations, corresponding to well-known extraordinary events, i.e. in the years 1973-74, 1978-79, 1986, 2009 .

Since the price of other energy is exogenous, an impulse of $25 \%$ at $t_{0}$ will raise this price by $25 \%$, for $t_{0}+1, t_{0}+2, t_{0}+3$ etc., resembling a tax increase. However, for the five subsectors analyzed in this section, electricity prices are only exogenous for Agriculture, Trade and Other services. For Construction and Machine- and vehicle manufacturing this is not the case and this implies that a $25 \%$ negative impulse at $t_{0}$ to electricity prices will not imply a long-run (permanent) decrease of $25 \%$, due to the feedback from the other variables on electricity prices. It is therefore more reasonable to normalize the impulse so that it produces a decrease of $25 \%$ in the long run in electricity prices and then look at the long-run effects on the intensities. This can be done by using the equations $C \delta=h$, where $C$ is the long-run impact matrix, $\delta$ is the impulse (unknown and to be solved for, for electricity prices) and $h$ includes the chosen long-run effects. See e.g. Møller (2008) for an example of this normalization, and Johansen (2005) for the general case.

The graphs of the impulse-response functions for the energy intensities are given in Figure 3 . The red and blue graphs correspond to electricity and other energy, respectively. The percentage change is shown on the vertical axis and the horizon is 35 years, since within this period all long-run values have been reached approximately (the horizontal axis). For the interpretation of the impulse-response graphs, define the long-run effect as the difference between the long-run value (i.e. the asymptote) and

\footnotetext{
${ }^{21}$ Recently, it has been estimated by the government that removing the PSO tariff and instead finance the support to renewable energy via the fiscal budget will imply a $25 \%$ reduction of the electricity bill for the average industrial end-user (see e.g. the home page of the Danish Ministry of Business and Growth). However, it remains unclear what the time horizon is, whether substitution has been allowed for and in general what assumptions are made about the future spot prices and thus the PSO payments to be financed.
} 
the starting point $(=0)$. Since this is the result of a $25 \%$ change, in the present experiments, one could accordingly define a long-run elasticity as the being $1 / 25$ of the long-run effect. Again it should be underscored that, in general, a long-run elasticity is not equal to a cointegrating coefficient (such as those from Table 4), since the former will generally depend on other parameters of the model. Nevertheless, in the simple CVAR models with one lag and exogeneity restrictions cointegrating coefficients coincide with the long-run elasticities, so that the long-run values in the impulse-response graphs are in fact equal to 25 times the cointegration estimates from Table 4. In particular, as explained below this is the case for Agriculture, Machine- and vehicle manufacturing, Trade and Other services.

Starting with Machine- and vehicle manufacturing, the long-run effect is a $10.20 \%$ increase in electricity and a $13.52 \%$ drop in other energy. These effects are driven only by the change in the price of other energy. This is due to the fact that, although the level of electricity prices adjusts to both relations, since it does not enter the cointegrating relations and since $k=1$, it has no short-run or long-run effect on the intensities. For Agriculture, Trade and Other services, where exogeneity holds for both $p r^{e}$ and $p r^{o}$, the interpretation is also rather straightforward, in that the long-run effect is simply the sum of own- and cross-price elasticities, multiplied by $25 .{ }^{22}$ Hence, the intensities of electricity in Agriculture, Trade and Other services increase by $8.19 \%, 8.37 \%$ respectively, and $21.47 \%$. For these three subsectors the intensity of other energy drops by respectively, $4.85 \%, 34.68 \%$ and $0 \%$. Note that the latter zero (long-run) effect reflects the zero (price) coefficients in $\widehat{\beta}_{2}$ in Table 4 . However, note also that these zero restrictions are merely statistical approximations. That is, these coefficients were insignificant and thus restricted to zero, but they had the expected signs. In other words the zero long-run effect on other energy for Other services (fifth panel, Figure 3), should be viewed as an approximation to an insignificant but negative effect.

Figure 3: Impulse response analysis showing the dynamic effects (in percentage) on the intensities of electricity (red) and other energy (blue) from a 25 percent permanent increase in the price of other energy and a long-run decrease of 25 percent in electricity prices.
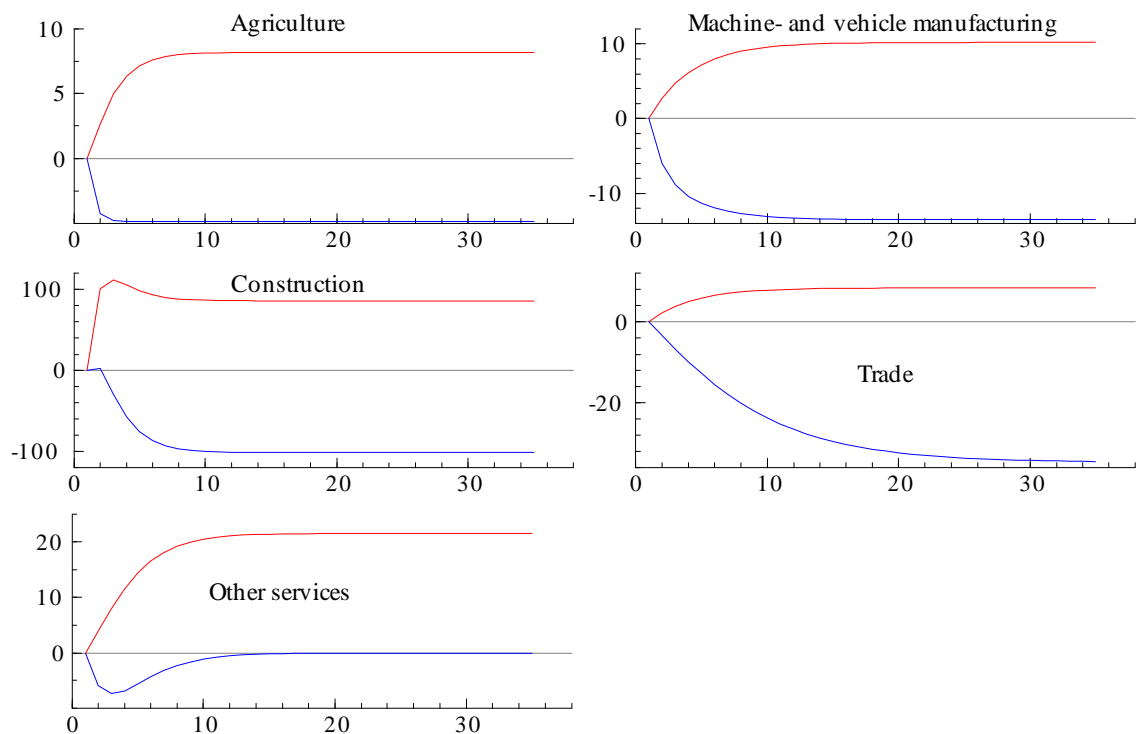

For Construction the impulse-response analysis is slightly more complicated due to more involved adjustment dynamics of the system, which is reflected in the non-zero adjustment coefficient in the first entry of $\widehat{\alpha}_{z}$. However, concerning the long-run effects (of the $25 \%$ long-run changes in both prices), the

${ }^{22}$ Note that, due to the above-mentioned error-correlation for Agriculture, the results for this subsector are more uncertain compared to the remaining. They may nevertheless give an overall impression. 
results suggest that for this sector a tax reform could be highly effective. In particular, in the long run the intensity of electricity rises by $85.85 \%$ while the intensity of other energy drops by as much as $101.50 \%$.

Finally, note that most of the long-run effect is reached within a decade for all five sectors, but also that there are differences in the adjustment process. For example, for Agriculture the long-run effect on other energy is already reached (roughly) after three years, whereas for Other services, the effect after three years is quite different from the corresponding long-run effect, which is reached after roughly 20 years.

To sum up, the impulse-response results are well-behaved and although there are differences in magnitudes across the subsectors, they suggest that changing relative prices by imposing taxes, can be a means of inducing substitution.

\section{Concluding remarks}

For each of eight subsectors of the Danish economy, together accounting for the bulk of aggregate industrial energy consumption and economic activity, this research has identified long-run demand relations for electricity and other energy (an aggregate of liquid fuels, coal, coke, gas, district heating and biomass). Conditional on a limited number of extraordinary events (oil crises, fiscal policy etc.) it was possible to obtain reasonably well-specified statistical models (partial CVARs) with constant parameters for the most part. Moreover, the estimation results obtained from the full sample covering 1966-2011 were, in general, reasonably robust. In particular, for five large subsectors, Agriculture, Machine- and vehicle manufacturing, Construction, Trade and Other services, the results seemed robust towards sample changes and the presence of a third cointegrating relation between relative prices (common to all subsectors). For these five subsectors, for which significant own-price and/or cross-price effects were found, an impulse-response experiment was carried out in order to investigate the potential for taxation to induce substitution of electricity for other energy and thus for greening industrial energy consumption. The experiment, which resembled a simple tax reform, described the combined long-run effect from raising the price of other energy with $25 \%$ while at the same time lowering the price of electricity by $25 \%$ (in the long run). The overall policy implication is that substitution from other energy towards electricity may be induced by taxation, when targeted towards these sectors. The experiment may throw some light on the potential consequences for industrial energy consumption (and thus tax revenues) of removing the Danish PSO tariff, which has recently been suggested for strengthening the competitiveness of the trade exposed industries, and increasing taxation on fossil-based energy as a means of financing this. Compared to financing by increasing the bottom-bracket taxes, as has been suggested in the Danish political debate, such a tax reform is of course likely to impact differently in terms of competitiveness but would presumably contribute more effectively to the green transition.

The disaggregate or subsectorial approach revealed large behavioural differences across the subsectors. For internationally integrated economies, such as the Danish, this insight contributes valuable information with respect to long-term forecasting of aggregate energy demand and substitution, since over longer time horizons, the subsector composition is bound to change substantially, for example as a result of increasing international trade.

The study contributes new insights to the literature on energy demand and substitution, which in spite of being vast contains very few econometric analyses which consider electricity demand and substitution at the subsector level.

A number of possible extensions and paths for future research to follow suggest themselves. For example, it could be fruitful to apply the present analysis to time series data from other countries. Obviously the other Scandinavian economies for which detailed high-quality data are also available, could be considered. However, also for developing countries, for which the subsector composition is likely to undergo 
large changes in the future, a disaggregate approach seems promising for improving long-term energy forecasting. Secondly, as mentioned the impulse-response experiment conducted here is to some extent stylized, and hence, could be augmented in order to consider more complex and realistic tax policies. From an econometric point of view there are also a number of extensions which could be interesting to consider. For example, as it appears from the time plots of the intensities these graphs are rather smooth. This suggests that, as an alternative to the present approach, which models ratio-transformed variables by an I(1) CVAR with trends and level shifts, one could consider an I(2) approximation, supposedly for the original variables. Another possibility is that the data are better modelled by including some non-linearity in the form of thresholds in the adjustment to the long-run equilibrium deviations (see e.g. Bec and Rahbek, 2004). For example, it seems reasonable that, an increase in the price of other energy has to be of some magnitude, in order for the consumer to react, in the sense of undertaking long-term investments in new electricity intensive capital.

\section{Acknowledgements}

I would like to thank Frits M. Andersen, Geraldine Henningsen, Henrik K. Jacobsen, Helge V. Larsen, Diana F. Møller, Thomas Thomsen and two anonymous referees for their useful comments. Funding from Innovation Fund Denmark is gratefully acknowledged.

\section{References}

Bec, F., Rahbek, A., December 2004. Vector equilibrium correction models with non-linear discontinuous adjustments. Econometrics Journal 7 (2), 628-651.

Bentzen, J., Engsted, T., January 1993. Short- and long-run elasticities in energy demand : A cointegration approach. Energy Economics $15(1), 9-16$.

Berndt, E. R., Wood, D. O., 1975. Technology, prices, and the derived demand for energy. The Review of Economics and Statistics $57(3), 259-68$.

Bernstein, R., Madlener, R., 2015. Short-and long-run electricity demand elasticities at the subsectoral level: A cointegration analysis for German manufacturing industries. Energy Economics 48, 178-187.

Doornik, J. A., 1995. 'Testing general restrictions on the cointegrating space'. Tech. rep., University of Oxford, Nuffield College.

Erdogdu, E., 2007. Electricity demand analysis using cointegration and ARIMA modelling: A case study of Turkey. Energy Policy $35(2), 1129-1146$.

Fouquet, R., Pearson, P., Hawdon, D., Robinson, C., Stevens, P., 1997. The future of UK final user energy demand. Energy Policy $25(2), 231-240$.

Galindo, L. M., 2005. Short- and long-run demand for energy in Mexico: a cointegration approach. Energy Policy 33 (9), $1179-1185$.

Johansen, S., 1992. Cointegration in partial systems and the efficiency of single equation analysis. Journal of Econometrics 52 (3), $389-402$.

Johansen, S., 1996. Likelihood-Based Inference in Cointegrated Vector Autoregressive Models. Advanced Texts in Econometrics, Oxford University Press, Oxford.

Johansen, S., 2005. Interpretation of cointegrating coefficients in the cointegrated vector autoregressive model. Oxford Bulletin of Economics and Statistics 67 (1), 93-104.

Juselius, K., 2006. The cointegrated VAR model: Econometric methodology and macroeconomics applications. Oxford University Press. 
Klinge Jacobsen, H., 2000. Energy demand, structural change and trade: A decomposition analysis of the Danish manufacturing industry. Economic Systems Research 12 (3), 319-343.

Knudsen, F., Smidt, J., 1994. Indledende forsøg på modellering af energiefterspørgslen (in Danish). Tech. rep., Statistics Denmark.

Lee, C.-C., Chang, C.-P., 2005. Structural breaks, energy consumption, and economic growth revisited: Evidence from Taiwan. Energy Economics $27(6), 857-872$.

Møller, N. F., Sharp, P., 2014. Malthus in cointegration space: evidence of a post-Malthusian pre-industrial England. Journal of Economic Growth 19 (1), 105-140.

Møller, N. F., 2008. Bridging economic theory models and the cointegrated vector autoregressive model. Economics: The OpenAccess, Open-Assessment E-Journal 2 (2008-21).

Møller Andersen, F., Jacobsen, H., Morthorst, P., Olsen, A., Rasmussen, M., Thomsen, T., Trier, P., 1998. EMMA: En energi- og miljørelateret satellitmodel til ADAM. Nationaløkonomisk Tidsskrift 136, 333-349.

Nasr, G. E., Badr, E. A., Dibeh, G., 2000. Econometric modeling of electricity consumption in post-war Lebanon. Energy Economics $22(6), 627-640$.

Nielsen, B., Rahbek, A., 2000. Similarity issues in cointegration analysis. Oxford Bulletin of Economics and Statistics 62 (1), 5-22.

Ozturk, I., 2010. A literature survey on energy-growth nexus. Energy Policy 38 (1), $340-349$.

Payne, J. E., January 2010. Survey of the international evidence on the causal relationship between energy consumption and growth. Journal of Economic Studies 37 (1), 53-95.

Pesaran, M. H., Smith, R., Akiyama, T., 1998. Energy demand in Asian developing economies. Oxford University Press.

Polemis, M., 2007. Modeling industrial energy demand in Greece using cointegration techniques. Energy Policy 35 (8), $4039-4050$.

Suganthi, L., Samuel, A. A., 2012. Energy models for demand forecasting-a review. Renewable and Sustainable Energy Reviews $16(2), 1223-1240$.

Yuan, J., Kang, J.-G., Zhao, C.-H., Hu, Z.-G., 2008. Energy consumption and economic growth: Evidence from China at both aggregated and disaggregated levels. Energy Economics 30 (6), 3077-3094.

Zachariadis, T., Pashourtidou, N., 2007. An empirical analysis of electricity consumption in Cyprus. Energy Economics 29 (2), $183-198$. 


\section{Appendices (supplementary material)}

\section{A. Description of the data}

The data consist of annual time series 1966-2011 from eight different subsectors of the Danish economy. Together these make up the bulk of total industrial energy consumption and economic activity, and represent the primary -, secondary - and tertiary sectors. To get an idea of magnitudes, note that with respect to aggregate industrial energy consumption (excluding transport energy), these eight industries accounted for $67 \%$ in $2005 .^{23}$ Each of the eight subsectors are aggregates of national accounts industries. These aggregations attempt to group the national accounts industry categories into relatively energy homogenous industries. Table 1 in Section 2.1 shows which particular national account industries are included in the eight subsectors.

The subsector representing the primary sector is referred to as Agriculture and includes horticulture and forestry in addition to agriculture. The energy intensity is high in this subsector, which, by 2005 terajoule (TJ) numbers, accounted for as much as $14 \%$ of the total industrial non-transport energy consumption. Agriculture, horticulture and forestry together account for almost all energy consumption of the primary sector. In general, energy is used for heating, operating of machines (electricity) and transportation related to fieldwork. In horticulture energy is used for heating greenhouses, and in particular, electricity is used for controlling and lighting. The distribution of all non-transport energy in this industry between electricity and other energy is $20 \%$ versus $80 \%$, suggesting a considerable potential for substitution.

The subsectors of the secondary sector comprise, Food manufacturing, Chemical manufacturing, Machine- and vehicle manufacturing, Other manufacturing and Construction. Together these subsectors account for about $80 \%$ of all energy consumption of the secondary sector. ${ }^{24}$ By 2005 TJ numbers, the food manufacturing subsector was as energy consuming as agriculture and hence accounted for as much as $13 \%$ of the total industrial non-transport energy consumption. The distribution of all non-transport energy in this industry between electricity and other energy is $25 \%$ versus $75 \%$. Chemical manufacturing accounted for $6 \%$ of the total industrial non-transport energy consumption, using the 2005 numbers. Of this, electricity accounted for $43 \%$ and other energy for $57 \%$. With respect to energy consumption and its distribution between electricity and other energy the machine and vehicle subsector mirrors chemical manufacturing. Other manufacturing accounted for $9 \%$ of the total industrial non-transport energy consumption, using the 2005 numbers. Of this, electricity accounted for $27 \%$ and other energy for $73 \%$. Considering the particular industries included in these subsectors (cf. Table 1) energy is used for lighting, refrigerating, cooling and heating, and for operating of machines (electricity). Finally, for Construction the corresponding number are $3 \%$ of the total industrial non-transport energy consumption, of which electricity accounted for $16 \%$ only.

The service sector of the economy is represented by two subsectors, referred to as Trade and Other services, of which the latter comprises a wide range of services (see Table 1). Together, these two industries account for around $60 \%$ of all energy consumption of the tertiary sector. ${ }^{25}$ Trade accounts for $10 \%$ of the total industrial non-transport energy consumption of which half originates from electricity. Although Other services is a large subsector, which by overall economic measures has been growing in size, this subsector contains the industries which are not particularly heavy when it comes to energy consumption. Nevertheless, together they account for $6 \%$ of the total industrial non-transport energy consumption, out of which $39 \%$ comes from electricity and $61 \%$ from other energy.

\footnotetext{
23 Source: Statistics Denmark.

${ }^{24}$ Using 2005 TJ numbers from Statistics Denmark.

${ }^{25}$ See Footnote 24
} 
For each of the eight subsectors, the time series variables of interest are the following: Electricity intensity, or electricity consumption per unit of output, $\frac{E_{t}}{Y_{t}}$, defined as the ratio of electricity consumption $\left(E_{t}\right)$, in gigajoule $(\mathrm{GJ})$, relative to Gross Output $\left(Y_{t}\right)$ in thousand Danish kroner at 2010-prices, chained values. The consumption of other energy (also in GJ) per unit of (Gross) output, or simply the intensity of other energy, is denoted as, $\frac{O_{t}}{Y_{t}}$, and is defined accordingly. Prices of electricity, $P_{t}^{E}$, and other energy, $P_{t}^{O}$, stated in Danish kroner per GJ and both deflated by the Gross Domestic Product deflator at factor cost, $P_{t}$, in 2010-prices, chained values. Statistics Denmark is the source of the data on these variables. Finally, as the exogenous weather-related variable, on which the partial model is conditioned, heating degree days are used. The heating degree data were originally obtained from Elværksstatistikken. Two observations (1966-67) were reconstructed based on an older time series by use of a simple regression.

\section{B. Misspecification tests}

\section{Agriculture}

Vector AR 1-2 test: $\quad F(32,75)=0.83540$ [0.7094]

Vector Normality test: $\mathrm{Chi}^{\wedge} 2(8)=17.794$ [0.0228]*

Vector ZHetero test: $\quad F(68,84)=0.84273$ [0.7668]

\section{Food manufacturing}

Vector AR 1-2 test:

vector Normality test: $\mathrm{Chi}^{\wedge} 2(8)=9.8425[0.2763]$

Vector ZHetero test: $\quad F(100,42)=1.5291[0.0616]$

Chemical manufacturing

Vector AR 1-2 test: $\quad F(32,38)=0.98288$ [0.5163]

Vector Normality test: $\mathrm{Chi}^{\wedge} 2(8)=17.504$ [0.0253]*

Machine- and vehicle manufacturing

Vector AR 1-2 test: $\quad F(32,75)=0.94376$ [0.5604]

Vector Normality test: $\mathrm{Chi}^{\wedge} 2(8)=28.344$ [0.0004]**

Vector ZHetero test: $\quad \mathrm{F}(64,84)=1.5347$ [0.0329]*

\section{Other manufacturing}

Vector AR 1-2 test: $\quad F(32,38)=1.5223[0.1071]$

Vector Normality test: $\mathrm{Chi}^{\wedge} 2(8)=8.0739$ [0.4263]

\section{Construction}

Vector AR 1-2 test: $\quad F(32,75)=1.0493[0.4204]$

Vector Normality test: $\mathrm{Chi}^{\wedge} 2(8)=33.812$ [0.0000]**

Vector ZHetero test: $F(64,84)=1.1180$ [0.3137]

\section{Trade}

Vector AR 1-2 test: $\quad F(32,86)=1.5019$ [0.0712]

Vector Normality test: $\mathrm{Chi}^{\wedge} 2(8)=11.244$ [0.1882]

Vector ZHetero test: $\quad \mathrm{F}(60,95)=1.3103[0.1185]$

\section{Other services}

Vector AR 1-2 test: $\quad F(32,67)=1.2303$ [0.2351]

Vector Normality test: $\mathrm{Chi}^{\wedge} 2(8)=22.464$ [0.0041] **

Vector ZHetero test: $\quad F(72,77)=1.0360[0.4385]$ 


\section{Estimates of trends and structural breaks}

Even though the main interest in this analysis eventually lies on own- and cross-price effects, the estimates of the coefficients of the deterministic components, i.e. trends and level shift dummy variables, in Table 4 are now briefly commented on.

Starting with the trend a relatively unanimous picture emerges. The trend coefficient estimates are for the most part negative, with the most pronounced exceptions in Other manufacturing and Construction. Taking Agriculture as an example, the negative trend estimate of 0.01 in the cointegrating relation, suggests that steady state electricity demand (per unit of output) shifts to the left in a (ey, $\left.p^{e}\right)$ diagram at an annual rate of $1 \%$, whereas the demand curve for other energy shifts $2 \%$ per year. ${ }^{26}$ As mentioned such gradual decrease in energy intensities most likely reflect energy savings resulting from gradual technological progress and the gains from economies of scale (fewer but larger and more efficient farms).

Although different dummies were needed for different subsectors, there are some common. First of all, the turn of the $60 \mathrm{~s}$ to the $70 \mathrm{~s}$ marks a significant shift in energy demand relative to output. In particular, for four subsectors, the years 1969-1970 were associated with a long-run upward shift in energy intensities, ranging from $17 \%$ (Other services) to $42 \%$ (Agriculture) for electricity and around $20 \%$ for other energy. There can be several reasons for this and it must be kept in mind that it is the ratio of energy to Gross Output that shifts, implying that both the numerator and the denominator could fall, but if the latter decreases the most, the ratio will increase. Here, the rise in the intensities for Agriculture and Food manufacturing were due to a recession in output, whereas for Machine and vehicle manufacturing and Other services there was a large increase in the consumption of other energy.

The years 1974/75 were the wake of the first energy crisis. It appears that the manufacturing industries, Machine- and vehicle, Chemical and Other, experienced large increases in electricity consumption, whereas there were no effect on the intensity of other energy. The increases in electricity intensity reflect an output reduction, as a result of the persistent economic downturn following the crisis. Oil consumption was reduced as resulting from the higher oil prices and if only partly substituted by coal, a reduction in the level of other energy would occur. The evidence is consistent with the latter reduction being of roughly a similar magnitude as the reduction in Gross Output, leaving the intensity of other energy unaltered. The next energy crisis in 1978/79, on the other hand, clearly reduced the intensity of other energy for the Food- and Chemical manufacturing and Other services, with 20\%, $43 \%$ and 11\%, respectively. This decrease could first of all reflect increased energy-saving investments and improved insulation in the longer term. Substitution to other energy carriers could also have taken place. In particular, for Foodand Chemical manufacturing there seems to have been some substitution towards electricity implying an increase in the electricity intensities of the same magnitude. However, for Agriculture the reverse seems to hold.

Finally, to some extent the periods around the years 1986 and 2009 also seem to stand out, supposedly as a result of highly contractionary fiscal policy and a large drop in oil prices, respectively.

\section{Robustness Analysis}

\section{D.1. Assessing robustness towards sample changes}

For all subsectors the estimations in Section 3 have been based on the full sample, i.e. all available information and are as such preferred over estimations based on subsamples. However, as a useful robustness check the purpose is now to estimate the models based on subsamples to check that the obtained conclusions do not depend critically on the inclusion of a smaller part of the sample.

\footnotetext{
${ }^{26}$ Detailed interpretations of cointegrated VAR models in terms of simple graphical diagrams (e.g. the demand and supply cross) are found in Møller (2008) and Møller and Sharp (2014).
} 
For this purpose, forward recursive estimation of the CVAR models, with the same restrictions as those imposed in Table 4, is now performed for each subsector. This recursive estimation is based on the idea of starting with a baseline sample of minimal length (given the number of parameters), in this case the first 20-25 years. The model is then estimated recursively, by increasing the sample beyond the baseline sample, adding one observation at a time. The resulting sequence of estimates (along with error bands) and test statistics are then plotted against the endpoints of the corresponding subsamples. The plots can then be used to assess whether the recursive estimates change significantly suggesting a violation of the model assumption of constant parameters. Moreover, they can be used to check whether the test conclusions, with respect to sign and significance of cointegrating estimates, and overall acceptance of the restrictions (p-value), change markedly in comparison with the full sample results.

Figures D.1 through D.8 below show the graphs of the forward recursive estimations for all eight subsectors. In each figure there are two types of recursive graphs, relating to cointegrating coefficients and the Likelihood Ratio (LR) test for the overall restriction, respectively. All panels except the last one show the recursive estimates of the most important cointegrating coefficients. That is, for both electricity and other energy, the own- and cross-price coefficients, and the coefficient with respect to heating degree days. The recursive graphs of the estimates are accompanied by \pm 2 standard deviations, which makes it possible to assess the robustness of the full-sample test conclusions towards the shorter subsamples. The last panel plots the recursively calculated LR test statistic corresponding to the overall test, with acceptance at the $1 \%$ level when the graph is below the line.

Before assessing the graphs it should be noted that since the baseline sample is relatively short, some variability in the beginning of the graphs of both the estimates and the LR statistic is always expected. Henceforth, this variability is referred to as short-sample uncertainty. Note also that, in the recursions the short-run parameter estimates are kept fixed at their full sample values. This approach often gives a more clear picture when it comes to assessing the constancy (or lack of) of the long-run parameters. This is because instability or structural changes in the short-run parameters, which in the present context is of less importance, will introduce more variability in the recursive graphs for the long-run estimates, even though long-run parameters are constant. In addition to this, instability in the short-run parameters also introduces more noise and hence variability in recursive standard deviations (error bands) which may affect the test conclusions.

Concerning the assumption of constant parameters it is noted that, with the exception of Chemical manufacturing and Construction, there are in general no pronounced significant changes in the graphs of the estimates. For Chemical manufacturing there are some supposedly significant changes around the mid-90s, whereas for Construction, this seems to be the case for other energy towards the end of the sample. However, in both cases magnitudes do not seem alarming. Hence, given the expected shortsample uncertainty and the fact that in practice there is always some minor variability throughout the graphs, parameter constancy seems to be a reasonable assumption.

For the LR test of the overall restrictions imposed in Table 4, in four out of the eight cases, the restrictions can be jointly accepted for all subsamples. For the remaining half, rejection takes place only in the beginning and can supposedly be ascribed to short-sample uncertainty, at least partly.

Focussing on the own and cross-price coefficients, the conclusions with respect to the significance of the full-sample cointegrating estimates in Table 4 are very robust. In particular, with the exceptions of the estimated own-price coefficient for electricity in Agriculture and the cross-price coefficient for other energy in Trade, all significance conclusions obtained in Table 4 hold. In addition, even for these two cases the graphs are relatively stable and the change from significance to insignificance is not large.

To sum up, given that some variability in the beginning of the recursive graphs is always anticipated due to short-sample uncertainty, the overall impression from the forward recursive analyses is that, parameter constancy seems reasonable, the overall restrictions seem to be accepted for the vast majority 
of subsamples, and finally, that the conclusions, as obtained in Table 4, with respect to significance of individual price coefficients, are rather robust towards the shorter subsamples.

Since the baseline sample is fixed (the first 20-25 observations) in all recursions, the forward recursive analysis cannot say anything about the influence on the estimation from the observations in the beginning of the sample. As the first 10-15 years include supposedly a structural break around 1970 and the two energy crises, robustness towards the exclusion of the first past of the sample was also assessed to complement the forward recursive estimation. However, it should be underscored that, given the limited number of observations (45), the full sample estimation, which conditions on these breaks by the use of level shifts dummies, and in particular for which it is possible to maintain statistical adequacy, is preferred over cutting off the first part of the sample. The resulting recursive plots for the overall p-value are given in Figure D.9. Note that, as opposed to before, now it is the p-value corresponding to the LR test statistic and not the statistic itself that is reported. Hence, acceptance at the $1 \%$ level occurs when the graph is above the blue line. Considering that the full-sample analysis takes the energy crises into account by use of the level shift dummy variables, the recursive graphs seem reasonable for five out of eight subsectors, namely Agriculture, Machine- and vehicle manufacturing, Constructions, Trade and Other services. For the latter it was however not possible for the likelihood to converge in the first part of the graph. For the three manufacturing industries (Food-, Chemical and Other), the full-sample conclusions are not robust. In particular, it seems that the first few observations could be the main driver of the obtained conclusions, although it should be reiterated that the full sample estimation conditions on the structural breaks by use of the level shift dummies.

Figure D.1: Results of forward-recursive estimations for Agriculture. The first five panels of the figure depict the respective estimated cointegrating coefficients, together with $95 \%$ confidence limits, against the end point of the recursive samples. The last panel shows the recursively calculated test statistic corresponding to the overall restriction on the $\alpha_{z}$ and $\beta$ matrices, where values above the blue line indicate a rejection of the restriction at the $1 \%$ significance level.
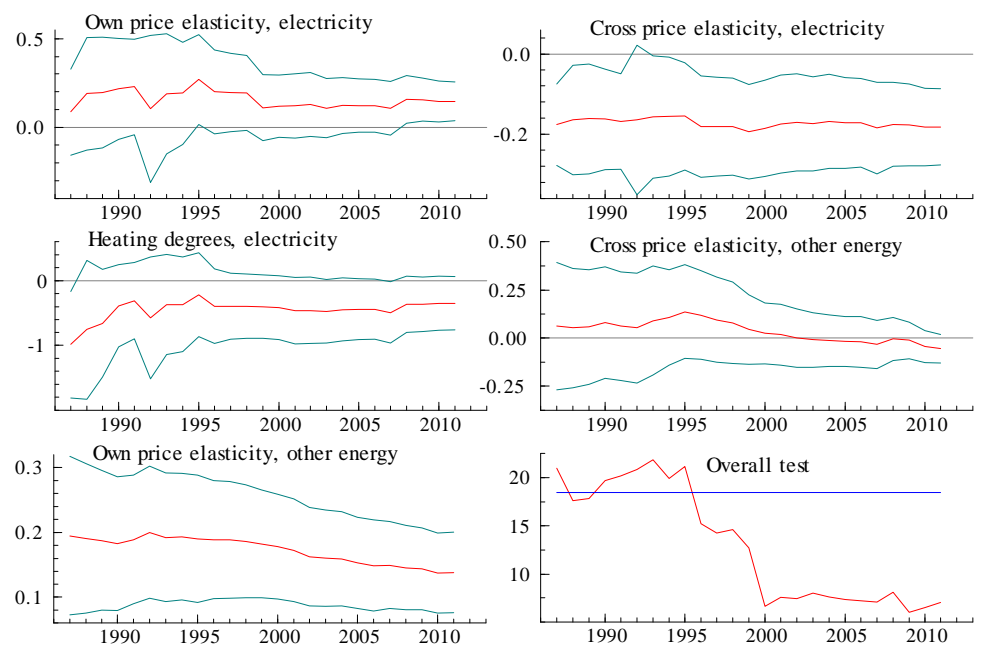
Figure D.2: Results of forward-recursive estimations for Food manufacturing. The figure is otherwise similar to Figure D.1.
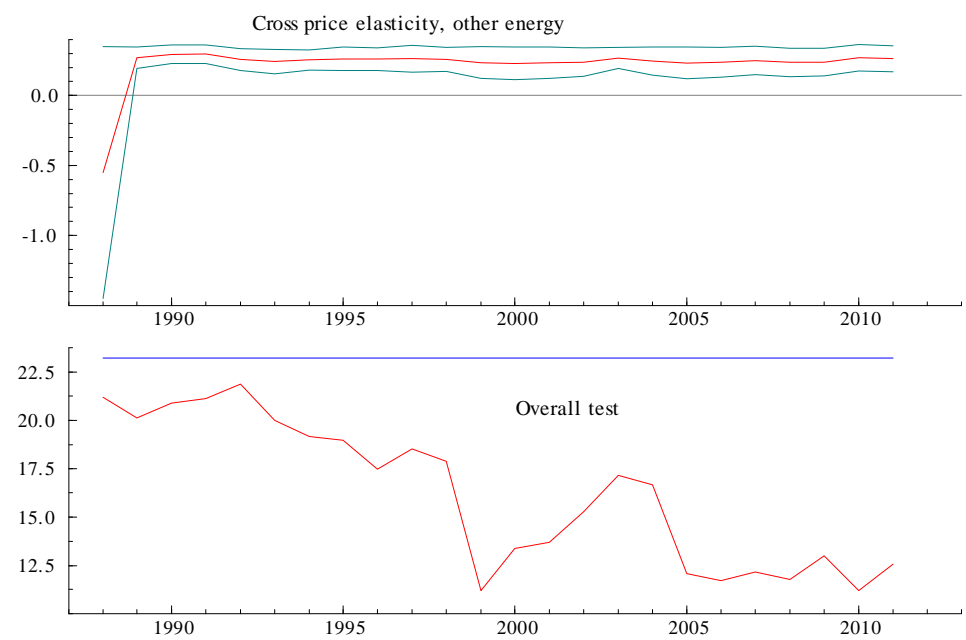

Figure D.3: Results of forward-recursive estimations for Chemical manufacturing. The figure is otherwise similar to Figure D.1.
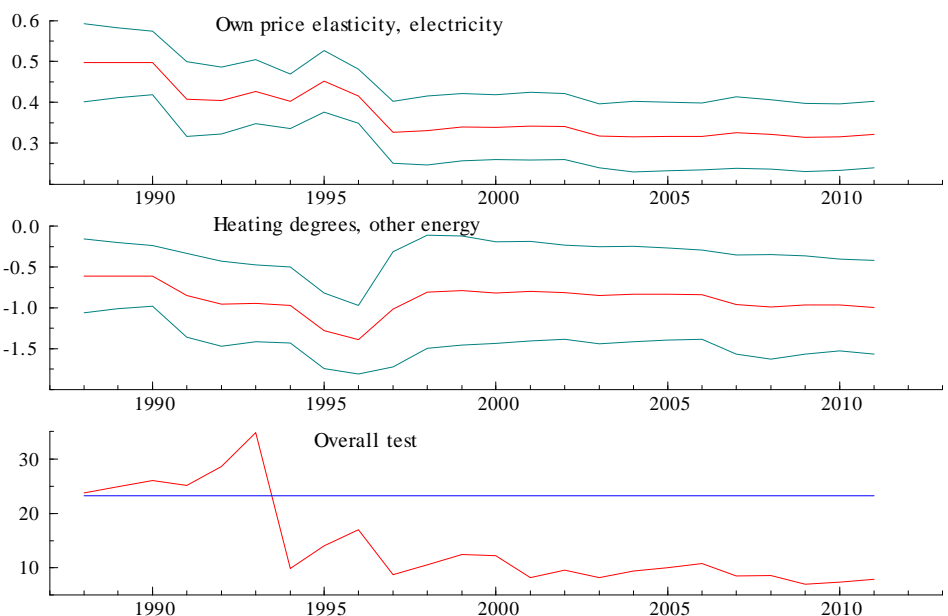
Figure D.4: Results of forward-recursive estimations for Machine- and vehicle manufaturing. The figure is otherwise similar to Figure D.1.
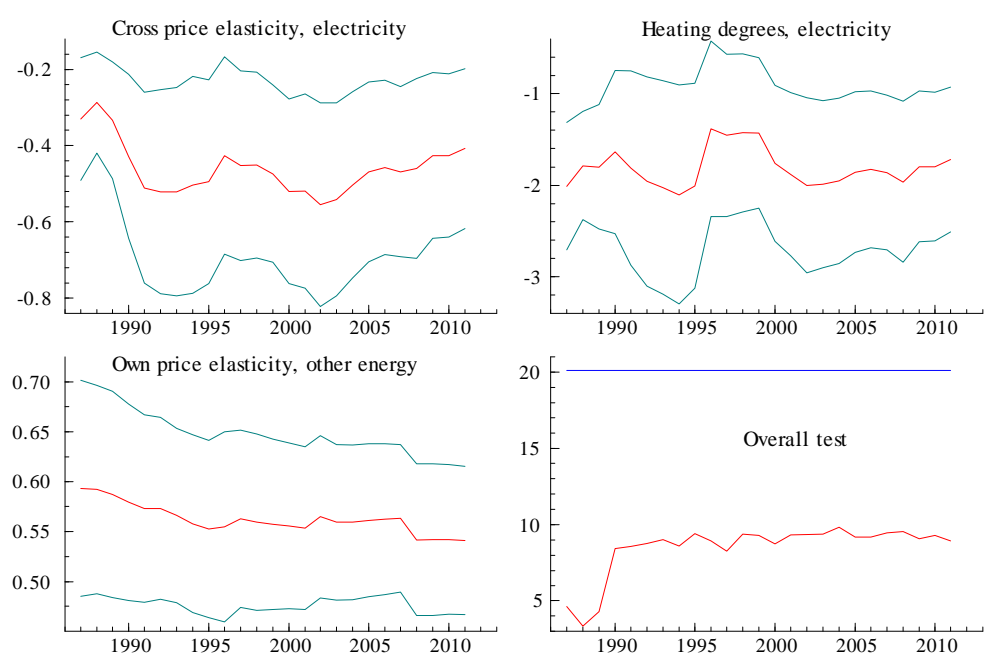

Figure D.5: Results of forward-recursive estimations for Other manufaturing. The figure is otherwise similar to Figure D.1.
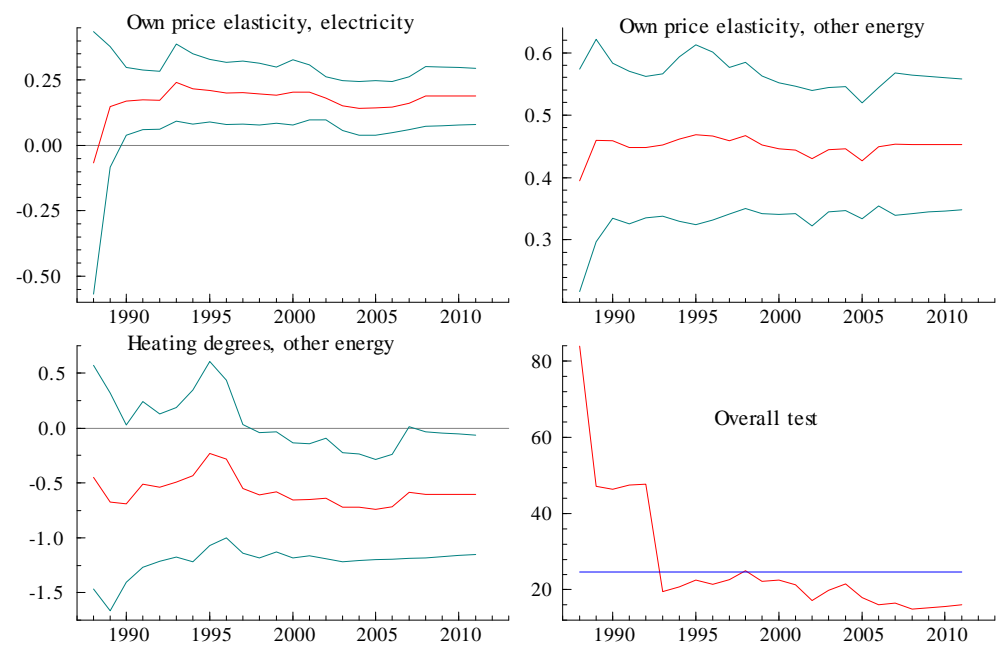
Figure D.6: Results of forward-recursive estimations for Construction. The figure is otherwise similar to Figure D.1.
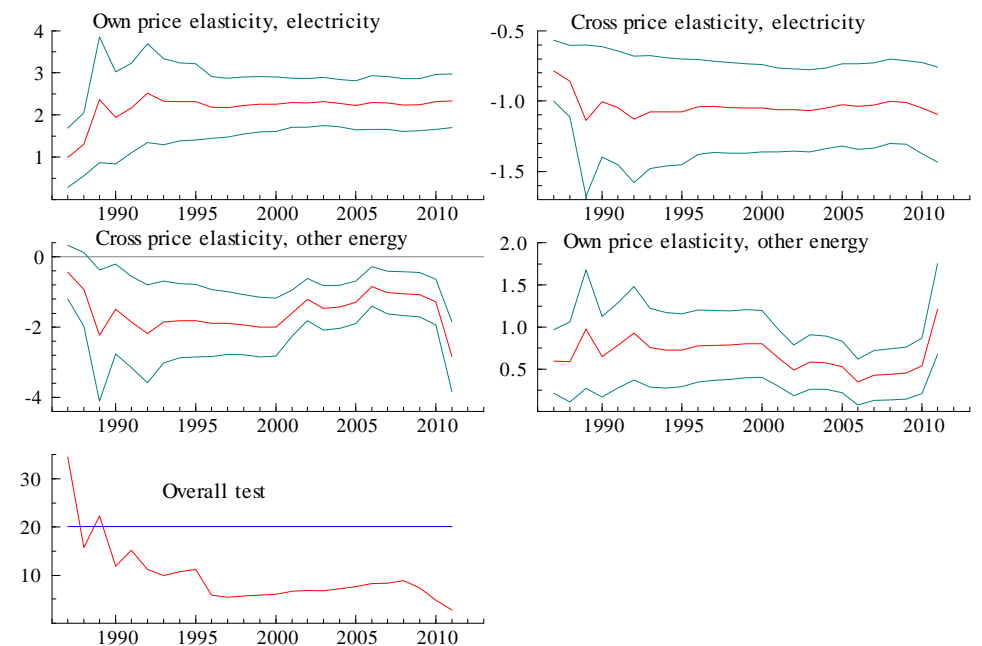

Figure D.7: Results of forward-recursive estimations for Trade. The figure is otherwise similar to Figure D.1.
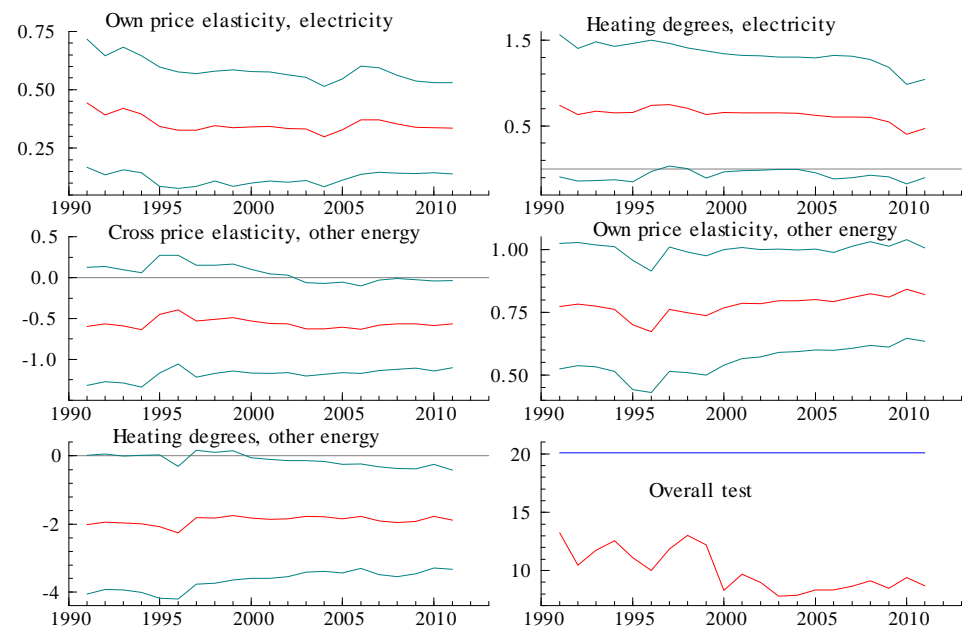
Figure D.8: Results of forward-recursive estimations for Other service. The figure is otherwise similar to Figure D.1.
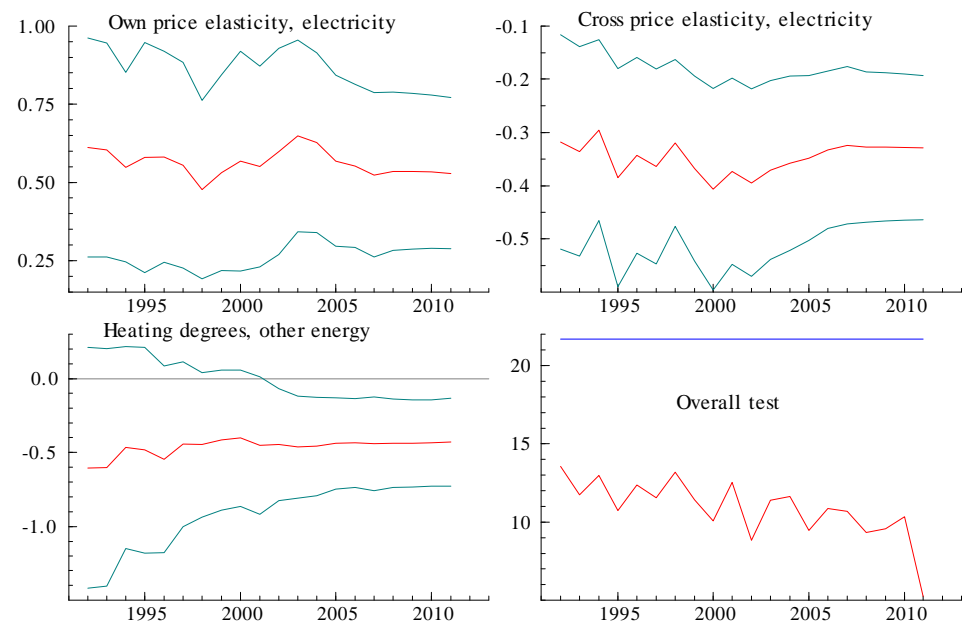

Figure D.9: P-value for the overall test for each of the eight industries. Comparison to blue 1-percentage line.
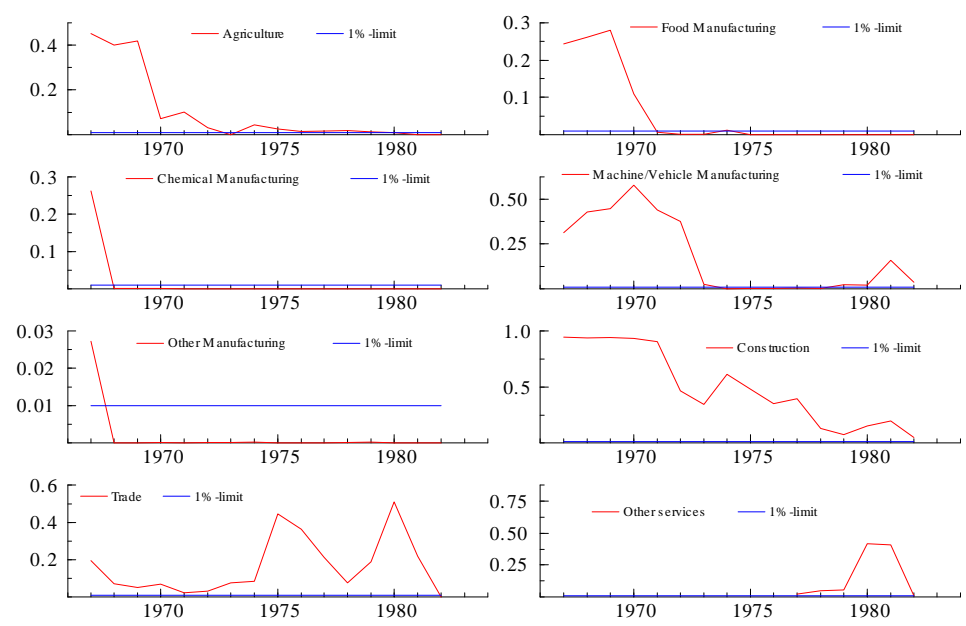

\section{D.2. Assessing robustness with respect to the cointegration rank}

Table 3 in Section 3 suggests that although two cointegrating relations is a reasonable choice, consistent with the working hypothesis, there is some indication of an additional cointegrating relation, although this is more relevant for some of the subsectors than others. In this appendix it is therefore attempted to identify an additional relation jointly with the existing restrictions on the two first cointegrating relations. The purpose is to assess the robustness of the estimates of the two existing cointegration relations towards adding a third relation and not the latter as such.

Since the number of restrictions on each cointegrating vector that are required for (just) identification equals $r-1$, there must now be at least two restrictions on each vector, which must fulfill the rank conditions for generic identification (see Chapter 5 in Johansen, 1996). ${ }^{27}$ As before, only the $r-1$

\footnotetext{
${ }^{27}$ This implies that, in case there is only one restriction on one of the existing cointegrating vectors and/or the rank condition failed, it was necessary to impose an additional restriction on the existing relation. However, this was only necessary for the electricity relation for Agriculture in Table 4, which has only one restriction.
} 
restrictions on $\beta$ needed for just identification were imposed on the new relation initially and then insignificant variables were removed from the cointegrating relations.

A third relation is to some extent expected. In particular, for each subsector bivariate plots of the relative input prices suggested that these two variables cointegrate (conditional on the breaks). Since some of the components, primarily coal but also oil, in particular, are inputs into electricity production, it is expected that the price level of these inputs will influence electricity prices in the longer term. Hence, the third relation is common for all eight subsectors. The price of these components (of other energy) should reasonably be exogenous to the Danish economy. Therefore, when augmenting with another cointegrating relation, it was an obvious approach to retain the assumption that the price of other energy was exogenous, i.e. a zero row in the $\alpha_{z}$ matrix. However, as this is a testable restriction this was tested and accepted in all cases except for Agriculture. On the other hand one would expect significant error correcting adjustment of the relative electricity price to the new relation. Therefore, for $\alpha_{z}$, only the first two adjustment coefficients in the row corresponding to the relative electricity price, were restricted to zero as before (when $r=2$ ). Finally, both intensities were initially allowed to adjust to the new relation and if insignificantly, the adjustment coefficients were set to zero.

Table D.1 below summarizes the estimates of the price coefficients from the first two cointegrating relations (the existing ones from Table 4), when the third relation is added. As the latter does not contain any parameters of interest for the given purpose, the estimates from this bivariate cointegration relationship between $p r_{t}^{e}$ and $p r_{t}^{o}$ are not reported. Likewise, the estimates from the adjustment matrix are also not reported, as these in general were unaltered and reflected significant error correction. The last column shows the p-value corresponding to the overall test of the new restricted cointegration model, i.e. with the two existing cointegrating vectors and the new one, against the unrestricted partial CVAR with $r=3$ as the only restriction. In comparison to Table 4 in Section 3, the table shows that in five out of the eight cases the estimated own and cross-price coefficients in the first two cointegrating relations are approximately unchanged with respect to sign, significance and magnitude.

Table D.1: Robustness of the previous cointegrating estimates towards the presence of a third cointegrating vector (between relative input prices).

\begin{tabular}{|c|c|c|c|c|c|}
\hline & $\widehat{\beta}_{11}=-\widehat{\gamma}_{e}$ & $\widehat{\beta}_{21}=-\widehat{\delta}_{e}$ & $\widehat{\beta}_{12}=-\widehat{\gamma}_{o}$ & $\widehat{\beta}_{22}=-\widehat{\delta}_{o}$ & p-value \\
\hline Agriculture & 0.00 & 0.00 & $\begin{array}{l}-0.06 \\
{[-1.65]}\end{array}$ & $\begin{array}{l}0.14 \\
{[4.57]}\end{array}$ & 0.03 \\
\hline Food Manufct. & 0.00 & 0.00 & $\begin{array}{l}0.26 \\
{[6.41]}\end{array}$ & 0.00 & 0.33 \\
\hline Chemical Manufct. & $\begin{array}{l}0.37 \\
{[9.31]}\end{array}$ & 0.00 & 0.00 & 0.00 & 0.36 \\
\hline Mach./Vehcl Manufct. & 0.00 & $\begin{array}{l}-1.73 \\
{[-3.22]}\end{array}$ & 0.00 & $\begin{array}{c}0.50 \\
{[10.22]}\end{array}$ & 0.17 \\
\hline Other Manufct. & $\begin{array}{l}0.17 \\
{[3.09]}\end{array}$ & 0.00 & 0.00 & $\begin{array}{l}0.46 \\
{[8.47]}\end{array}$ & 0.31 \\
\hline Construction & $\begin{array}{l}2.21 \\
{[13.43]}\end{array}$ & $\begin{array}{l}-1.02 \\
{[-6.14]}\end{array}$ & 0.00 & 0.00 & 0.87 \\
\hline Trade & $\begin{array}{l}0.35 \\
{[3.49]}\end{array}$ & 0.00 & $\begin{array}{l}-0.57 \\
{[-2.10]}\end{array}$ & $\begin{array}{l}0.81 \\
{[8.66]}\end{array}$ & 0.16 \\
\hline Other services & $\begin{array}{l}0.63 \\
{[6.42]}\end{array}$ & $\begin{array}{l}-0.25 \\
{[-3.41]}\end{array}$ & 0.00 & 0.00 & 0.14 \\
\hline
\end{tabular}

The most important exception, relating to the electricity relation, is that for Agriculture, for which both own and cross-price coefficients become insignificant (and are therefore set to zero). Also, for Machine- and vehicle manufacturing there is some change in magnitudes, as the estimated cross-price coefficient changes from 0.41 to 1.73 , albeit sign and significance are robust. For Construction the lack of robustness concerns the relation for other energy. Hence, the results seem generally relatively robust. 